\title{
PADRÕES DE COBERTURA E USO DA TERRA E SUA INFLUÊNCIA NA TEMPERATURA DO AR EM RIO CLARO, SP
}

\author{
Gustavo ARMANI \\ Carolina Leocádio PEREIRA \\ Sérgio Ricardo CHRISTOFOLETTI
}

\begin{abstract}
RESUMO
A modificação dos padrões de cobertura e uso da terra de um determinado lugar resulta em alterações na temperatura do ar. A partir desta premissa, este trabalho teve como objetivo analisar os gradientes de temperatura do ar entre cinco locais com diferentes padrões de cobertura e uso da terra, situados na Floresta Estadual Edmundo Navarro de Andrade (FEENA), Rio Claro (SP), e na área urbana do mesmo município. A temperatura do ar foi amostrada a cada $30 \mathrm{~min}$ por meio de registradores digitais autônomos, entre setembro de 2010 e agosto de 2011 em cinco padrões de ocupação da terra: 1) floresta de árvores nativas, 2) reflorestamento de eucalipto com sub-bosque de árvores nativas, 3) reflorestamento de eucalipto, 4) área urbana mista industrial, comercial e residencial, 5) área urbana residencial e comercial. Com os dados consistidos foram realizadas análises estatísticas de posição, dispersão, regressão/correlação e de séries temporais. Estes resultados foram organizados em tabelas, gráficos e diagramas temporo-espaciais para revelar a estrutura térmica e suas relações com os padrões de cobertura e uso da terra. Os padrões de ocupação com características urbanas apresentam maior diferença térmica em relação à floresta de árvores nativas, com desvios médios de $1,7{ }^{\circ} \mathrm{C}$ no outono e primavera, e de $2,0^{\circ} \mathrm{C}$ no verão e inverno. A baixa variação altimétrica entre os postos da FEENA foi suficiente para mascarar em vários casos a influência das diferenças de vegetação, indicando que o efeito topoclimático se sobrepôs ao microclimático sob determinados tipos de tempo. Na área urbana o efeito topoclimático não foi suficientemente forte para atenuar a influência da mudança da cobertura e uso da terra e da energia dissipada pela dinâmica urbana. Essa influência pôde ser percebida pelas diferenças nas amplitudes térmicas, desvios em relação à temperatura da floresta de árvores nativas e pela modificação do ritmo térmico relacionada à dissipação de calor proveniente das atividades humanas (ciclo de sete dias).
\end{abstract}

Palavras-chave: cobertura e uso da terra, temperatura do ar, clima urbano, Rio Claro.

\section{ABSTRACT}

PATTERNS OF COVERAGE AND LAND USE AND THEIR INFLUENCE ON THE AIR TEMPERATURE IN RIO CLARO, SP. Changes in the coverage patterns and land use in a given place result in changes in air temperature. From this premise, this study aimed to analyze the air temperature gradients in five sites with different coverage patterns and land use, situated between the State Forest Edmundo Navarro de Andrade (FEENA), Rio Claro (SP), and the urban area of the same municipality. Between September 2010 and August 2011, the air temperature was measured every 30 min by dataloggers in five sites with different land use patterns: 1) forest of native trees, 2) eucalyptus reforestation with understory native trees, 3) eucalyptus forestry, 4) industrial mixed urban, commercial and residential areas, and 5) residential and commercial urban area. After data consistency, statistical analyses of position, dispersion, regression/correlation, and time series were performed. The results are shown in tables, graphs and spatial-temporal diagrams and reveal the thermal structure 
and its relationship with the coverage and land use patterns. Urban settlement patterns have higher temperature variations when compared to forest of native trees, with mean deviation of $1.7{ }^{\circ} \mathrm{C}$ in the fall and spring, and $2.0^{\circ} \mathrm{C}$ in the summer and winter. In several cases, the small altitude variation among the posts of the FEENA was enough to mask the influence of differences in the vegetation, indicating that the topoclimatic effect overlapped the microclimatic one under certain weather types. In urban areas the topoclimatic effect was not strong enough to mitigate the influence of changes in coverage and land use, and of the energy dissipated by urban dynamics. Its influence can be seen in the differences in temperature range, the deviations of the temperature of the native forest trees, and in the change in the thermal rhythm related to heat dissipation from human activities (seven-day cycle).

Keywords: coverage patterns and land use, air temperature, urban climate, Rio Claro.

\section{INTRODUÇÃO}

A capacidade do ser humano alterar o clima não ocorre a partir de uma ação direta na atmosfera, cuja essência do dinamismo está relacionada em geral à escala do globo, mas a uma ação indireta, ou seja, na modificação da cobertura biótica da crosta terrestre, principiando pela comunidade vegetal (MONTEIRO 1978).

De fato, o ser humano tem a capacidade de "criar" ou interferir nos climas das chamadas escalas inferiores (microclimas, topoclimas, mesoclimas) e alterar parcialmente os climas locais ou sub-regionais. Daí para as escalas superiores essa influência tende a ser cada vez mais rarefeita e de difícil detecção. Disso resulta que parte das alterações do clima decorrentes da ação humana, sobretudo em áreas urbanas, tem um caráter reversível em prazos muito curtos (possivelmente semanas ou meses) (AZEVEDO 2001a).

Segundo MONTEIRO (1978) a dinâmica atmosférica interligada aos processos naturais "organiza" espaços climáticos a partir das escalas superiores (zonal, regional) às inferiores (local, topo e microclima), enquanto a ação humana em derivar ou "alterar" essa organização ocorre no sentido inverso.

É conveniente notar que MONTEIRO (1978), ao assumir o ser humano como "derivador" da natureza, conduz a discussão das mudanças das condições geoecológicas originais de um lugar sem atribuir um juízo de valor, uma vez que qualquer derivação pode, a princípio, ser positiva ou negativa.

Estudos sobre clima urbano são uma necessidade, pois o processo de urbanização em cidades de países em desenvolvimento impõe a degradação da qualidade ambiental. O espaço urbano altera o balanço de energia no ambiente principalmente em função dos seguintes fatores: a) tipo de material de cobertura da superfície; b) formas das estruturas urbanas; e, c) fontes de calor e de umidade antropogênicas e qualidade do ar (poluição). Essa alteração no balanço de energia resulta em mudanças nos valores de temperatura e umidade relativa do ar, que nada mais são do que respostas deste balanço.

A necessidade de conhecer as propriedades do ar (calor, luz, composição) nos espaços da escala humana, onde se reproduz a vida enquanto totalidade (respirar, trabalhar, habitar), é um fato inquestionável (TARIFA 2001). As cidades brasileiras, em geral, oferecem expressivos exemplos de desrespeito ecológico e falta de criatividade no aproveitamento do quadro natural para a implantação das cidades. Esse retrato revela, antes de qualquer outro fato, uma hostilidade, se não uma aversão, à natureza (MONTEIRO \& TARIFA 1977). O crescimento desordenado das áreas urbanas traz consigo uma série de problemas, tais como inundações, escorregamentos e desconforto térmico. Tal fato tem despertado a sociedade, ainda que tardiamente, para as questões de qualidade ambiental, principalmente no que se refere ao aumento da temperatura, poluição do ar e redução da umidade relativa, resultando, quase sempre, em uma derivação antropogênica negativa em relação às condições geoecológicas originais do lugar.

Os geossistemas primitivos do território paulista já foram ocupados e derivados, em diferentes graus e aspectos, em praticamente sua totalidade (MONTEIRO 1978). Vários estudos buscaram compreender alguns efeitos dessas derivações antropogênicas no clima em diversas regiões do Estado de São Paulo, tais como em São Paulo (LOMBARDO 1985; AZEVEDO 2001a, b; TARIFA \& ARMANI 2000, 2001; JARDIM 2001; ARMANI et al. 2008), São José dos Campos (TARIFA 1981), Sorocaba (TAVARES 2002), Rio Claro (SANTOS JUNIOR \& CHRISTOFOLETTI 2008, ARMANI et al. 2010), 
Piracicaba (COLTRI et al. 2007), Penápolis (SILVA et al. 2002), Presidente Prudente (AMORIN 2000), Ourinhos (CARFAN 2011, SOUZA \& NERY 2011), entre outras. Os resultados indicam que o aumento da temperatura e redução da umidade relativa nas áreas urbanas estão relacionados à reduzida presença e má distribuição da vegetação dentro da área urbana. Cabe ressaltar que nem sempre essa situação prevalece, tal como demonstrou TARIFA (1981) ao analisar a ilha de calor em São José dos Campos (SP). Conforme o autor, dependendo da alternância de ritmos, havia momentos em que preponderava o aquecimento na zona rural, enquanto em outros, na área urbana.

Os modos de influência humana na determinação de um clima urbano provêm da transformação da energia adquirida pela estrutura urbana (MONTEIRO 1976) e da dissipação do calor proveniente das atividades humanas (AZEVEDO 2001b).

Partindo-se da premissa de que não só a estrutura urbana, mas também o ritmo das atividades humanas é um dos elementos determinantes da derivação antrópica do sistema climático, tal como observado por AZEVEDO (2001a) na Região Metropolitana de São Paulo (RMSP), cabe também discutir se em cidades médias esse ritmo chegaria a influenciar os climas, pelo menos em suas escalas inferiores (topo e microclimas).

Rio Claro é uma cidade paulista de médio porte, com 188.019 habitantes (em 2011) (SEADE 2012). A Floresta Estadual "Edmundo Navarro de Andrade" - FEENA, criada pelo Decreto n. ${ }^{\circ} 46.819$ de 11 de junho de 2002, posicionada a leste da área urbana é um "obstáculo" à expansão da cidade (Figura 1). Desta forma, entre a FEENA e a área urbana de Rio Claro existem diferentes padrões de cobertura e de uso da terra, onde o nível de interferência humana e social apresenta diferentes graus e intensidades em sua composição, contendo áreas de mata nativa, de reflorestamento, densamente urbanizadas e de ocupação consolidada.

Assim, a hipótese a ser discutida nesse trabalho é que as mudanças na cobertura e ocupação da terra induzem modificações na temperatura do ar, uma função do balanço de energia por unidade de tempo em um espaço tridimensional. Este trabalho analisa os gradientes de temperatura do ar entre cinco locais com diferentes tipos de coberturas e uso da terra, situados entre a cidade de Rio Claro e a FEENA.

\section{2 ÁREA DE ESTUDO}

A área de estudo situa-se na Média Depressão Periférica Paulista (ALMEIDA 1964), aproximadamente no centro do Estado de São Paulo, entre as coordenadas $22^{\circ} 21^{\prime}$ e $22^{\circ} 27^{\prime}$ de latitude Sul, e $47^{\circ} 31^{\prime}$ 'e $47^{\circ} 36^{\prime}$ de longitude Oeste. Trata-se de um compartimento topograficamente rebaixado entre o Planalto Atlântico, a leste, e as cuestas basálticas, a oeste, constituído por colinas amplas com altitudes que variam de 600 a $670 \mathrm{~m}$.

Segundo CARMO (2006) a topografia aplainada na área de Rio Claro facilitou o estabelecimento de um núcleo urbano com desenho em tabuleiro de xadrez. Todavia, a uniformidade da malha urbana foi perdida com a expansão da cidade de forma desarticulada com o planejamento original. A cidade tem se expandido de forma mais significativa nos trechos norte e oeste (ROSETTI et al. 2007).

Em praticamente 30 anos a população de Rio Claro (urbana + rural) quase dobrou, ou seja, partiu de 109.821 habitantes em 1980 para 188.019 em 2011 (SEADE 2012), em um ritmo de crescimento praticamente constante (taxa aproximada de 2.500 habitantes. $a n o^{-1}$ ). É considerada uma cidade de médio porte, segundo o Instituto Brasileiro de Geografia e Estatística (IBGE 2014). A maior parte da população do município (>97\%) é urbana (SEADE 2012). A área do município é de $498 \mathrm{~km}^{2}$, sendo que $28,35 \mathrm{~km}^{2}$ referem-se à área urbanizada (5,7\% da área total).

A leste da área urbana e contígua a ela está a FEENA, antigo Horto Florestal, atualmente classificada como Unidade de Conservação de Uso Sustentável. Trata-se de um grande maciço florestal com $22,3 \mathrm{~km}^{2}$ de área, composto principalmente por talhões de diferentes espécies de eucaliptos, alguns com espécies nativas em regeneração natural formando sub-bosque junto aos eucaliptos, e outros específicos de espécies nativas. O entorno da FEENA e da área urbana é ocupado por plantações de cana-de-açúcar (Figura 1).

O Ribeirão Claro, com orientação N-S, serve de limite físico entre a área urbana e a FEENA (Figura 1). Paralelo a este ribeirão, a oeste, está o Córrego da Servidão, envolvido pela urbanização. Estas duas drenagens são afluentes do Rio Corumbataí, que neste trecho também apresenta orientação N-S. As amplitudes altimétricas destes vales em geral não ultrapassam $50 \mathrm{~m}$ e apresentam distância interfluvial de $3.000 \mathrm{~m}$.

Essas características morfológicas da rede de drenagem e do relevo conferem à cidade características de um sítio urbano aberto e divergente. A urbanização que se sobrepõe a essa topografia é de baixa complexidade (simples), conforme proposta de classificação de MONTEIRO (1990b). 

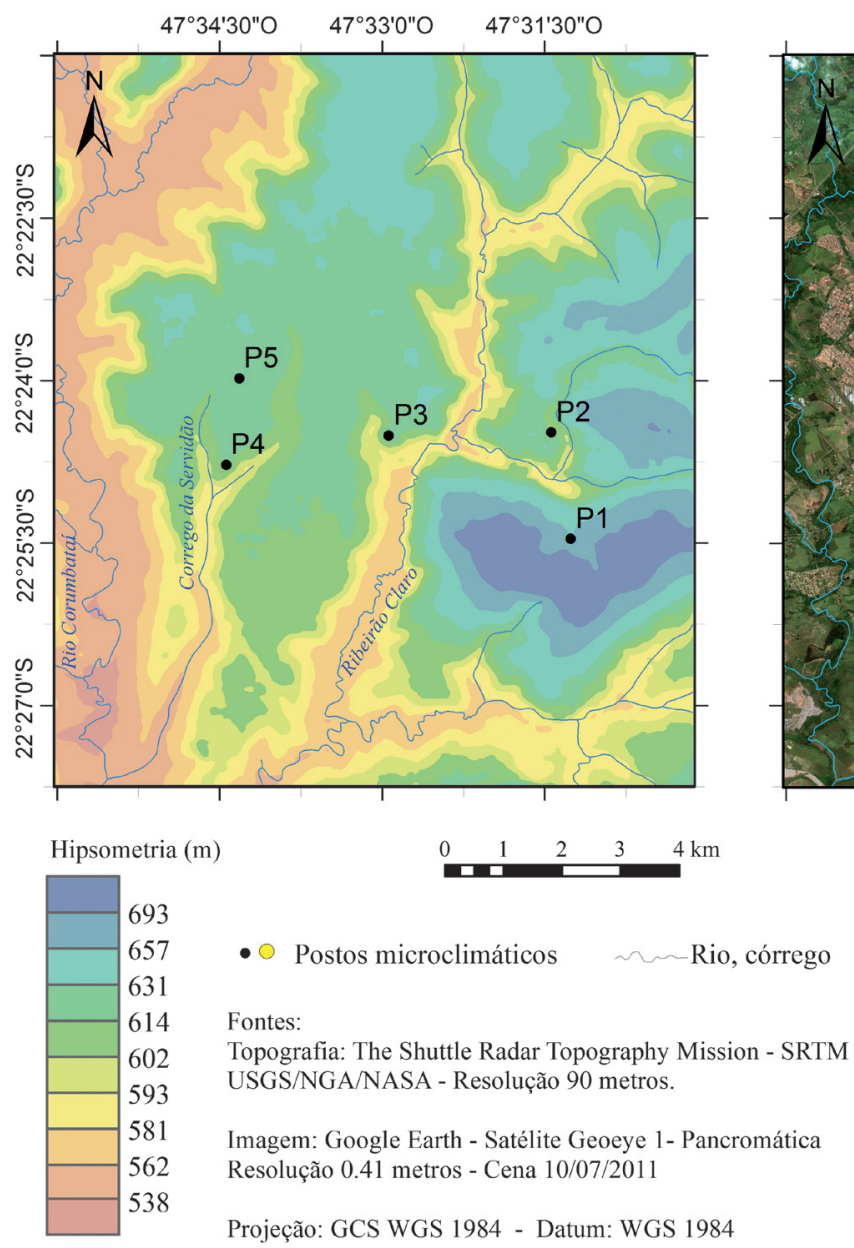

Projeção: GCS WGS 1984 - Datum: WGS 1984

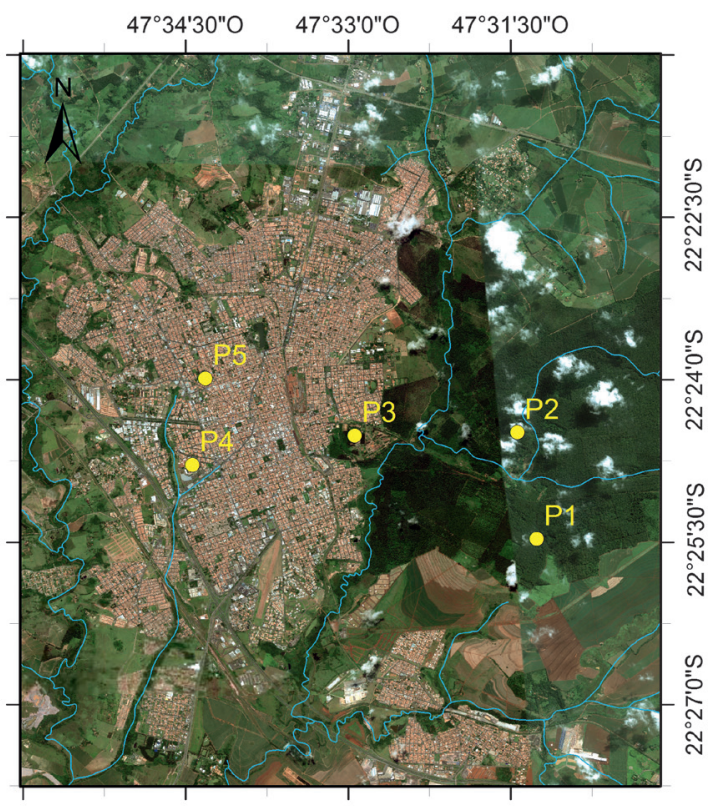

Localização da área no Estado de São Paulo

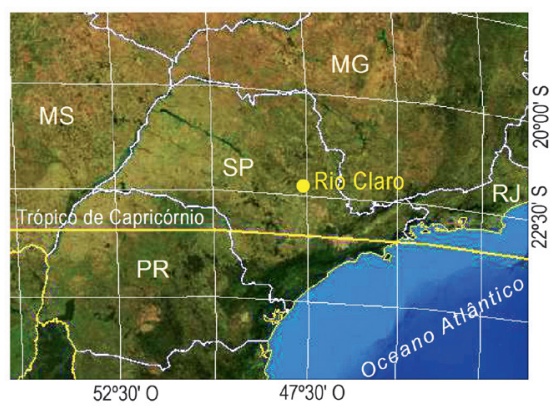

FIGURA 1 - Localização da área de estudo.

Inserida na zona intertropical e distante 222 km do Oceano Atlântico no trecho banhado pela Corrente do Brasil (temperaturas superiores a $22^{\circ} \mathrm{C}$ ), a área caracteriza-se por um clima regional controlado por massas equatoriais e tropicais alternadamente secas e úmidas, individualizado pelo ritmo da circulação atmosférica regional, que se justapõe às diversificações do relevo, e tem como característica fundamental a definição de período seco no inverno (MONTEIRO 1973). Trata-se de uma área com frequente participação do Sistema Tropical Atlântico e reduzida nebulosidade e umidade do ar, normalmente provocadas pela subsidência de ar superior. A média anual da temperatura oscila entre $18,1^{\circ} \mathrm{C}$ a $20,9^{\circ} \mathrm{C}$; no mês mais frio a temperatura média varia entre $2,7^{\circ} \mathrm{C}$ e $17,1^{\circ} \mathrm{C}$, com definição de seca nesse período; no mês mais quente a média da temperatura é frequentemente superior a $22{ }^{\circ} \mathrm{C}$ (CEAPLA/IGCE-
-UNESP 2014). Os ventos predominantes na área são SE, E e NE (SÃO PAULO 2012).

O período chuvoso ocorre de outubro a março, com 55 a 60 dias de chuva, totalizando cerca de $80 \%$ das precipitações anuais (média de 1.400 $\mathrm{mm}$ ). O período menos chuvoso ocorre preferencialmente entre abril e setembro, com 15 a 20 dias de chuva (CEAPLA/IGCE-UNESP 2014).

Essas características conferem a esta área um clima tropical típico, com uma estação chuvosa e outra seca.

\section{MATERIAIS E MÉTODOS}

Para avaliar os efeitos dos padrões de cobertura e uso da terra na temperatura do ar, partiu-se da premissa que os processos físicos, biológicos e humanos estão historicamente acumulados em um determinado lugar e, desta forma, a compreensão do clima revela-se por meio das relações de espa- 
ço-tempo. Salienta-se que há uma superposição temporal entre os controles climáticos de uma determinada ordem de grandeza com outros de ordem inferior e o número de variáveis que intervém nos processos e nos fluxos altera-se de acordo com o atributo climático e a escala de análise.

Conforme classificação dos canais da percepção humana para análise do clima urbano (MONTEIRO 1976), que tem o ser humano como referencial dos problemas e valores dos fatos geográficos, o presente estudo insere-se no canal do conforto térmico. Engloba, pois, componentes termodinâmicas que, em suas relações, se expressam por meio do calor, ventilação e umidade. A "[...] resolução termodinâmica seria a própria 'co-participação' advinda das transformações energéticas introduzidas pela ação humana na ci- dade, alterando, deformando ou ampliando aquela entrada natural [de energia] no sistema". (MONTEIRO 1990a, p.10 - grifo nosso).

3.1 Instrumental de campo e localização das estações microclimáticas

Registradores digitais autônomos de temperatura do ar foram instalados em cinco postos microclimáticos (P1 a P5) em diferentes padrões de cobertura e uso da terra entre a área urbana de Rio Claro e a FEENA (Tabela 1, Figuras 1 e 2), classificados conforme proposta adaptada de CPLA/IG (2013). Para minimizar o efeito da topografia na temperatura do ar as estações foram posicionadas em altitudes semelhantes e, sempre que possível, próximas aos topos das colinas.

TABELA 1 - Localização dos postos microclimáticos e padrão de cobertura e uso da terra. Densidade de ocupação: Alta - predominância de lotes de até $250 \mathrm{~m}^{2}$; Média - predominância de lotes de $250 \mathrm{~m}^{2}$ a $450 \mathrm{~m}^{2}$. Estágio de ocupação: Consolidado - áreas com mais de 80\% de área ou lotes ocupados com edificações; Em consolidação - áreas em fase de consolidação, apresentando entre 30\% a $80 \%$ de área ou lotes construídos; Rarefeito - áreas com ocupação incipiente (em estágio inicial), apresentando menos de $30 \%$ de área ou lotes edificados. Ordenamento da ocupação: combinação de 3 elementos básicos que compõem a estrutura urbana arborização urbana, pavimentação e traçado do sistema viário.

\begin{tabular}{|c|c|c|c|c|c|c|c|}
\hline \multirow{2}{*}{$\begin{array}{c}\text { Posto } \\
\text { (Latitude, } \\
\text { Longitude) }\end{array}$} & \multirow[b]{2}{*}{$\begin{array}{l}\text { Alt. } \\
\text { (m) }\end{array}$} & \multirow{2}{*}{$\begin{array}{c}\text { Nivel I } \\
\text { Cobertura } \\
\text { da Terra }\end{array}$} & \multirow{2}{*}{$\begin{array}{l}\text { Nivel II } \\
\text { Tipologia do } \\
\text { uso da terra } \\
\text { (atividade) }\end{array}$} & \multicolumn{4}{|c|}{ Nivel III Padrão da ocupação } \\
\hline & & & & Padrão & Densidade & Estágio & Ordenamento \\
\hline $\begin{array}{l}P 1 \\
\text { Talhão das Nativas } \\
\left(\mathrm{S} 22^{\circ} 25,472^{\prime}\right. \\
\left.\text { O } 47^{\circ} 31,252^{\prime}\right)\end{array}$ & 660 & $\begin{array}{l}\text { Vegetação } \\
\text { arbórea }\end{array}$ & $\begin{array}{l}\text { Parque (espaço } \\
\text { verde urbano) }\end{array}$ & $\begin{array}{l}\text { Mata primária } \\
\text { (árvores nativas) }\end{array}$ & - & - & - \\
\hline $\begin{array}{c}P 2 \\
\text { Trilha da Coleção } \\
\text { (eucaplitos }+ \text { nativas) } \\
\left(\mathrm{S} 22^{\circ} 24,487^{\prime}\right. \\
\left.\mathrm{O} 47^{\circ} 31,438^{\prime}\right)\end{array}$ & 625 & $\begin{array}{l}\text { Vegetação } \\
\text { arbórea }\end{array}$ & $\begin{array}{c}\text { Parque (espaço } \\
\text { verde urbano) }\end{array}$ & $\begin{array}{c}\text { Reflorestamento } \\
\text { com sub-bosque } \\
\text { de árvores } \\
\text { nativas }\end{array}$ & - & - & - \\
\hline $\begin{array}{c}P 3 \\
\text { Eucliptos citriodora sp } \\
\left(\mathrm{S} 22^{\circ} 24,620^{\prime}\right. \\
\left.\mathrm{O} 47^{\circ} 32,922^{\prime}\right)\end{array}$ & 630 & $\begin{array}{l}\text { Vegetação } \\
\text { arbórea }\end{array}$ & $\begin{array}{l}\text { Parque (espaço } \\
\text { verde urbano) }\end{array}$ & $\begin{array}{l}\text { Refloresta- } \\
\text { mento }\end{array}$ & - & - & - \\
\hline $\begin{array}{c}P 4 \\
\text { Faculdade Claretianas } \\
\left(\mathrm{S} 22^{\circ} 24,787^{\prime}\right. \\
\left.\mathrm{O} 47^{\circ} 31,4366^{\prime}\right)\end{array}$ & 620 & $\begin{array}{l}\text { Área } \\
\text { urbana }\end{array}$ & $\begin{array}{l}\text { Área edificada } \\
\text { \& loteamentos }\end{array}$ & $\begin{array}{c}\text { Edificações } \\
\text { horizontais } \\
\text { e algumas } \\
\text { verticais } \\
\text { dispersas }\end{array}$ & $\begin{array}{l}\text { Média } \\
\text { e Alta }\end{array}$ & $\begin{array}{c}\text { Consolidado, } \\
\text { em } \\
\text { Consolidação, } \\
\text { e Rarefeito }\end{array}$ & $\begin{array}{c}\text { Alto e Muito } \\
\text { Alto }\end{array}$ \\
\hline $\begin{array}{c}P 5 \\
\text { UNESP } \\
\left(\mathrm{S} 22^{\circ} 24,001^{\prime}\right. \\
\left.\mathrm{O} 47^{\circ} 34,327^{\prime}\right)\end{array}$ & 628 & $\begin{array}{l}\text { Área } \\
\text { urbana }\end{array}$ & Área edificada & $\begin{array}{l}\text { Edificações } \\
\text { horizontais }\end{array}$ & Alta & Consolidado & Muito alto \\
\hline
\end{tabular}

Padrões de cobertura e uso da terra adaptado de CPLA/IG (2013) 

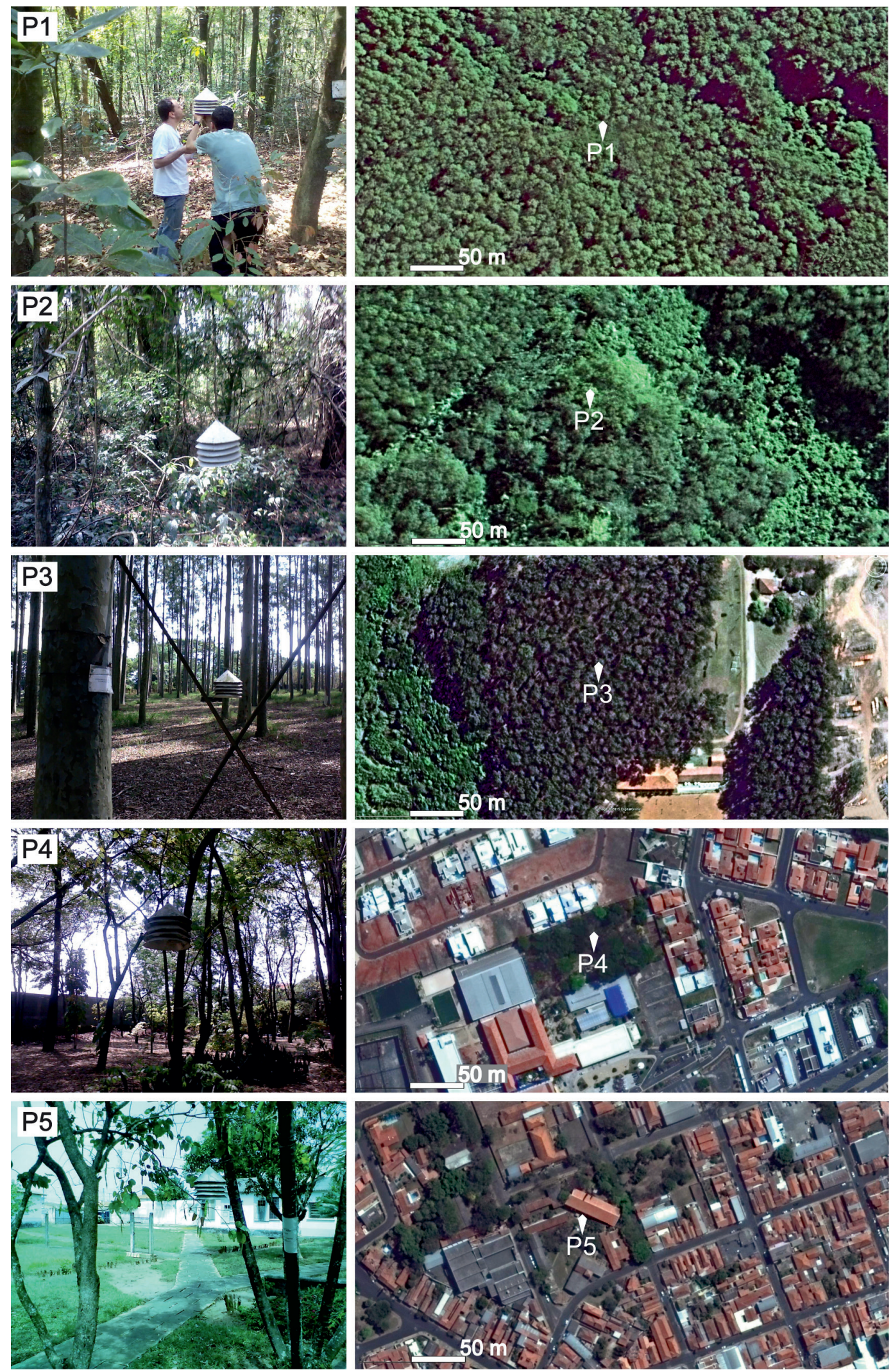

FIGURA 2 - Cobertura e uso da terra no entorno dos postos microclimáticos (P1 a P5). Imagens extraídas do Google Earth em 2015. 
Os sensores de temperatura tem exatidão (accuracy) de $\pm 0,2{ }^{\circ} \mathrm{C}$ e precisão de $0,01^{\circ} \mathrm{C}$. Isso implica que qualquer diferença existente entre os locais de medida deve ser maior que o erro instrumental, ou seja, $0,4{ }^{\circ} \mathrm{C}$. Definiu-se a frequência de amostragem e registro de dados para 30 minutos. Este intervalo é capaz de abranger grande parte dos ritmos climáticos.

Os registradores foram instalados em miniabrigos meteorológicos, conforme modelo desenvolvido por ARMANI \& GALVANI (2006), e instalados a uma altura de $1,70 \mathrm{~m}$ do solo, representativo do que VOOGT \& OKE (1997) denominaram de nível do pedestre.

Esses procedimentos procuraram assegurar que os cinco locais de instalação dos postos abrangessem os aspectos representativos da cobertura e uso da terra do entorno onde foram instalados.

\subsection{Segmento temporal analisado e tratamento estatístico dos dados}

A temperatura do ar foi monitorada entre $1 \mathrm{de}$ setembro de 2010 a 31 de agosto de 2011 com uma resolução de amostragem de 30 minutos.

Os dados brutos passaram por um controle de qualidade, conforme proposto no guia de instrumentos meteorológicos e métodos de observação da Organização Meteorológica Mundial (World Meteorological Organization - WMO 2007). Aqueles considerados inconsistentes foram excluídos e substituídos por uma estimativa realizada por regressão linear múltipla entre os outros quatros postos em um curto segmento temporal, referente ao período da falha. Os dados substituídos não representaram $0,01 \%$ da amostragem total de dados.

Com os dados consistidos foram realizadas as seguintes análises estatísticas: média mensal por posto; amplitude térmica máxima mensal (diferença entre a média das máximas diárias e as médias das mínimas diárias de cada mês); regressão linear de P2, P3, P4 e P5 em relação a P1, com definição do modelo estatístico linear (equação) e seu coeficiente de determinação $\left(\mathrm{R}^{2}\right)$; média horária em cada posto por dia da semana; desvio padrão; desvio absoluto entre as temperaturas dos postos P2, P3, P4 e P5 em relação ao $\mathrm{P} 1$; análise espectral de Fourier para determinação dos períodos (ciclos harmônicos) existentes nas séries de temperatura.

Os diagramas temporo-espaciais foram produzidos no programa Surfer ${ }^{\circledR} 12.0$ considerando a distância linear entre os postos, calculada com o método de interpolação polinomial local, que apresentou menor resíduo na análise estatística. Já para os diagramas de desvios médios horários entre $\mathrm{P} 1 \mathrm{e}$ os outros postos utilizou-se como método interpolador a krigagem com variograma linear, também escolhido em função dos menores resíduos.

Para testar a hipótese de que o ritmo das atividades humanas influencia no aumento da temperatura do ar da cidade e, consequentemente, no aumento da amplitude térmica entre cidade e floresta, foram calculadas as médias horárias de temperatura por dia da semana e o desvio absoluto entre as temperaturas dos postos $\mathrm{P} 2, \mathrm{P} 3, \mathrm{P} 4$ e P5 em relação ao P1, conforme proposto por AZEVEDO (2001a).

\section{RESULTADOS E DISCUSSÃO}

As diferenças de temperatura registradas, que são as respostas ao balanço de energia por unidade de tempo no espaço tridimensional, foram explicadas pelos fundamentos teóricos baseados no modo de recepção, transmissão, propagação e dissipação da energia em cada lugar monitorado. Esses ambientes microclimáticos na interface solocobertura da superfície-atmosfera (canopy layer) respondem às alterações na cobertura e uso da terra, tanto espacial, como vertical, alterando o modo de propagação e dissipação de energia.

A alteração no balanço de energia sobre as cidades ocorre em função do (1) tipo de material da cobertura da superfície, (2) forma e dimensão da estrutura urbana, (3) fontes de calor antropogênico, (4) fontes de umidade e (5) composição do ar (qualidade/poluição). O grau de influência de cada um desses controles varia no tempo e no espaço e depende de cada cidade e de sua história de produção no espaço geográfico.

No período monitorado as médias mensais das temperaturas nos pontos da área urbana de Rio Claro (P4 e P5) foram sempre maiores do que as encontradas nos pontos na FEENA (P1, P2 e P3). Os menores gradientes térmicos entre área urbana e floresta ocorreram nos meses de outono (abril e maio) e primavera (outubro), com diferenças de $1,7^{\circ} \mathrm{C}$, e os maiores nos meses do verão (dezembro/2010, janeiro e fevereiro/2011) e inverno (agosto/2011), com valores em torno de $2,0^{\circ} \mathrm{C}$ (Figura 3, Tabela 2).

A diferença na temperatura média mensal entre P1 e P2 (FEENA) só foi significativa $\left(>0,4{ }^{\circ} \mathrm{C}\right)$ em junho de 2011. Nesta ocasião P2 (Trilha da Coleção) apresentou temperaturas médias $0,8^{\circ} \mathrm{C}$ inferior a P1 (Talhão das Nativas) (Figura 3, Tabela 2). 
TABELA 2 - Temperaturas médias mensais, anual, máxima e minima absolutas e desvios absolutos médios mensais, anual, máximo e mínimo absoluto entre os postos P1 e P2, P3, P4 e P5.

\begin{tabular}{lccccccccc} 
& \multicolumn{3}{c}{ Tmed $\left({ }^{\circ} \mathrm{C}\right)$} & & \multicolumn{5}{c}{$\Delta$ Tmed $_{P_{x}-P 1}\left({ }^{\circ} \mathrm{C}\right)$} \\
\cline { 2 - 9 } & $P 1$ & $P 2$ & $P 3$ & $P 4$ & $P 5$ & $P 2-P 1$ & $P 3-P 1$ & $P 4-P 1$ & $P 5-P 1$ \\
\hline set/10 & 20,5 & 20,5 & 21,3 & 22,0 & 22,3 & 0,0 & 0,7 & 1,5 & 1,8 \\
out/10 & 20,1 & 20,1 & 20,9 & 21,2 & 21,6 & 0,0 & 0,9 & 1,1 & 1,5 \\
nov/10 & 21,2 & 21,2 & 22,6 & 23,1 & 23,6 & 0,0 & 1,4 & 2,0 & 2,4 \\
dez/10 & 22,3 & 22,5 & 23,6 & 23,9 & 24,4 & 0,2 & 1,3 & 1,6 & 2,1 \\
jan/11 & 22,4 & 22,6 & 23,6 & 23,9 & 24,4 & 0,2 & 1,2 & 1,6 & 2,0 \\
fev/11 & 22,5 & 22,9 & 23,9 & 24,2 & 24,5 & 0,4 & 1,4 & 1,7 & 2,0 \\
mar/11 & 21,2 & 21,5 & 22,3 & 22,5 & 22,7 & 0,3 & 1,1 & 1,3 & 1,5 \\
abr/11 & 19,8 & 19,8 & 20,9 & 21,5 & 21,5 & 0,0 & 1,1 & 1,7 & 1,7 \\
mai/11 & 16,6 & 16,3 & 17,4 & 18,4 & 18,3 & $-0,3$ & 0,8 & 1,8 & 1,7 \\
jun/11 & 15,3 & 14,5 & 15,9 & 17,0 & 16,7 & $-0,8$ & 0,6 & 1,7 & 1,4 \\
jul/11 & 17,1 & 17,1 & 17,8 & 19,0 & 18,7 & 0,0 & 0,7 & 1,9 & 1,6 \\
ago/11 & 18,7 & 18,7 & 19,6 & 20,8 & 20,7 & 0,0 & 1,0 & 2,1 & 2,0 \\
Média & 19,5 & 19,6 & 20,4 & 21,2 & 21,4 & 0,1 & 0,9 & 1,7 & 1,9 \\
Mín. Abs. & 4,2 & 2,5 & 2,9 & 5,4 & 5,0 & $-5,3$ & $-3,8$ & $-3,8$ & $-5,0$ \\
Máx. Abs. & 33,6 & 33,2 & 35,3 & 34,4 & 38,8 & 3,9 & 7,9 & 7,8 & 8,7 \\
\hline
\end{tabular}

$\mathrm{x}$ variando de 2 a 5

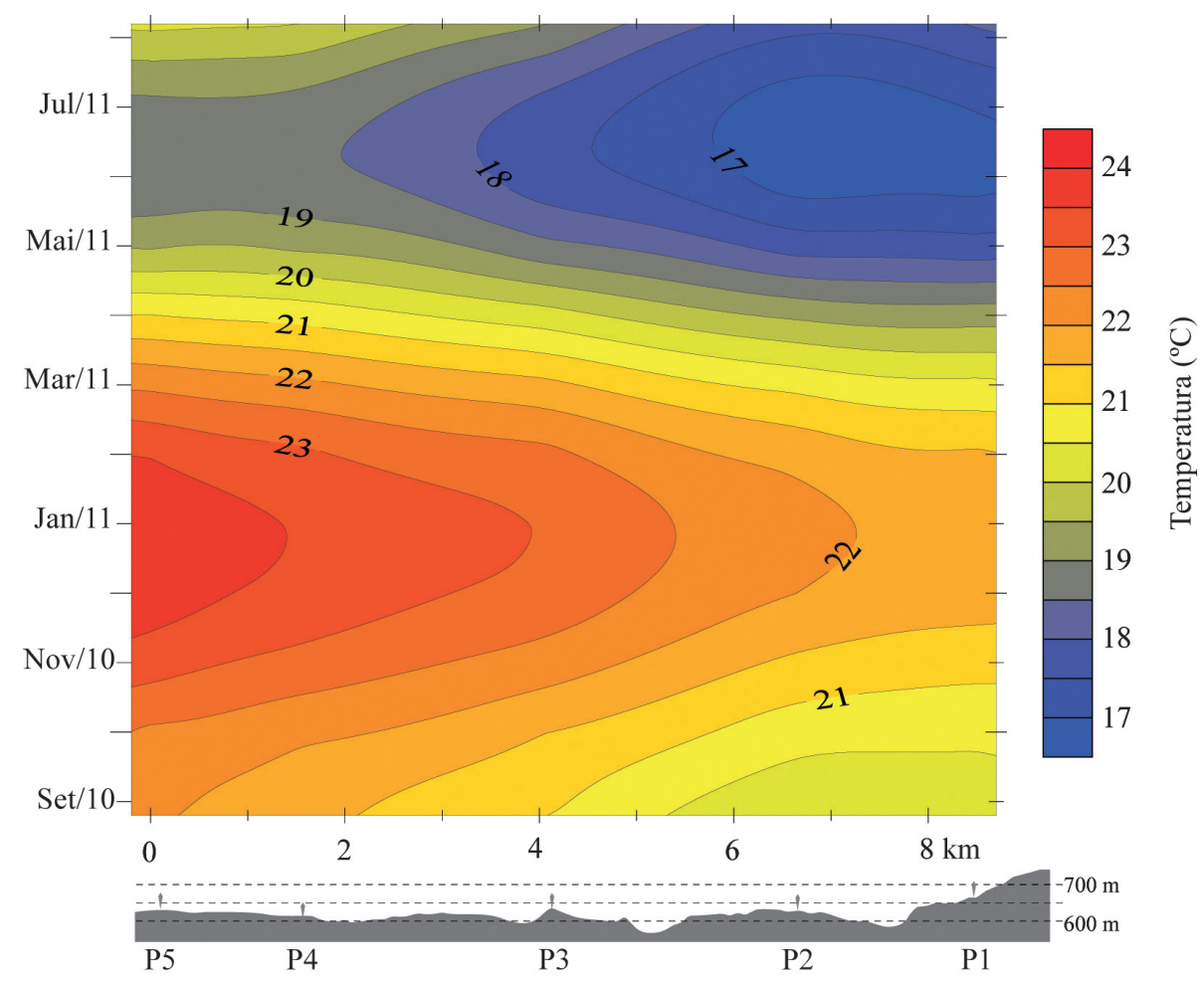

FIGURA3 - Variação temporo-espacial das temperaturas médias mensais do período monitorado (setembro/2010 a agosto/2011) entre a FEENA e a área urbana de Rio Claro. 
Nos postos situados na área urbana (P4 e P5) as diferenças entre as temperaturas médias foram significativas $\left(>0,4{ }^{\circ} \mathrm{C}\right)$ nos meses de verão, com P4 (Faculdade Claretianas) $0,5{ }^{\circ} \mathrm{C}$ inferior a P5 (UNESP) (Figura 3, Tabela 2).

A temperatura média mensal no posto 3 (Eucaliptos citriodora $s p$ ) pode ser caracterizada como transição floresta-cidade, pois apresentou valores intermediários durante todos os meses monitorados, embora sejam mais próximos daqueles da cidade (Figura 3, Tabela 2). Desta maneira, pode-se assumir que este posto reflete o aumento relativamente súbito ("cliff") da temperatura do ar no contato entre o ambiente florestal (ou rural) e urbano, conforme modelo de ilha de calor proposto por OKE (1982).

A amplitude média mensal da temperatura (média das diferenças entre as temperaturas máximas e as mínimas diárias registadas no mês) observada nos postos revelou que dentro da floresta a amplitude térmica foi sempre menor que na área urbana da cidade, oscilando entre $8^{\circ} \mathrm{C}$ nos meses de verão e $9-12{ }^{\circ} \mathrm{C}$ no inverno. Na área urbana a amplitude térmica mensal variou entre $9-10{ }^{\circ} \mathrm{C}$ no verão e entre $10-13{ }^{\circ} \mathrm{C}$ no inverno. Assim, no verão as amplitudes são menores, e aumentam progressi- vamente do outono para o inverno (Figura 4). Esse fato guarda estreita relação com a dinâmica já bem conhecida do clima tropical típico, quando na estação seca o menor teor de umidade no ar contribui para maiores amplitudes térmicas ao longo do dia e dos meses. Nessas ocasiões a temperatura na floresta oscila menos que nas áreas urbanas, uma vez que apresenta naturalmente maior umidade disponível em função da maior evapostranpiração proveniente das plantas e do solo.

$\mathrm{Na}$ floresta (postos P1, P2 e P3) a proteção da vegetação possibilita certo isolamento térmico do ambiente, criando volumes de ar com trocas (horizontais e verticais) de energia e matéria $\left(\mathrm{H}_{2} \mathrm{O}\right)$ mais lentas, o que proporciona menores contrastes entre as temperaturas máximas e mínimas. $\mathrm{Na}$ área urbana a elevada densidade de construções (residências e edifícios) e de estruturas geradoras e acumuladoras de calor promove aumento na taxa de aquecimento, como pode ser demonstrado na maior amplitude térmica da área urbana (P4 e P5).

A partir das análises de regressões entre os postos $\mathrm{P} 2$, P3, P4 e P5 em relação a P1, verifica-se que quanto maior o grau de modificação das condições geoecológicas originais de um lugar, menor é o coeficiente de determinação (Figura 5).

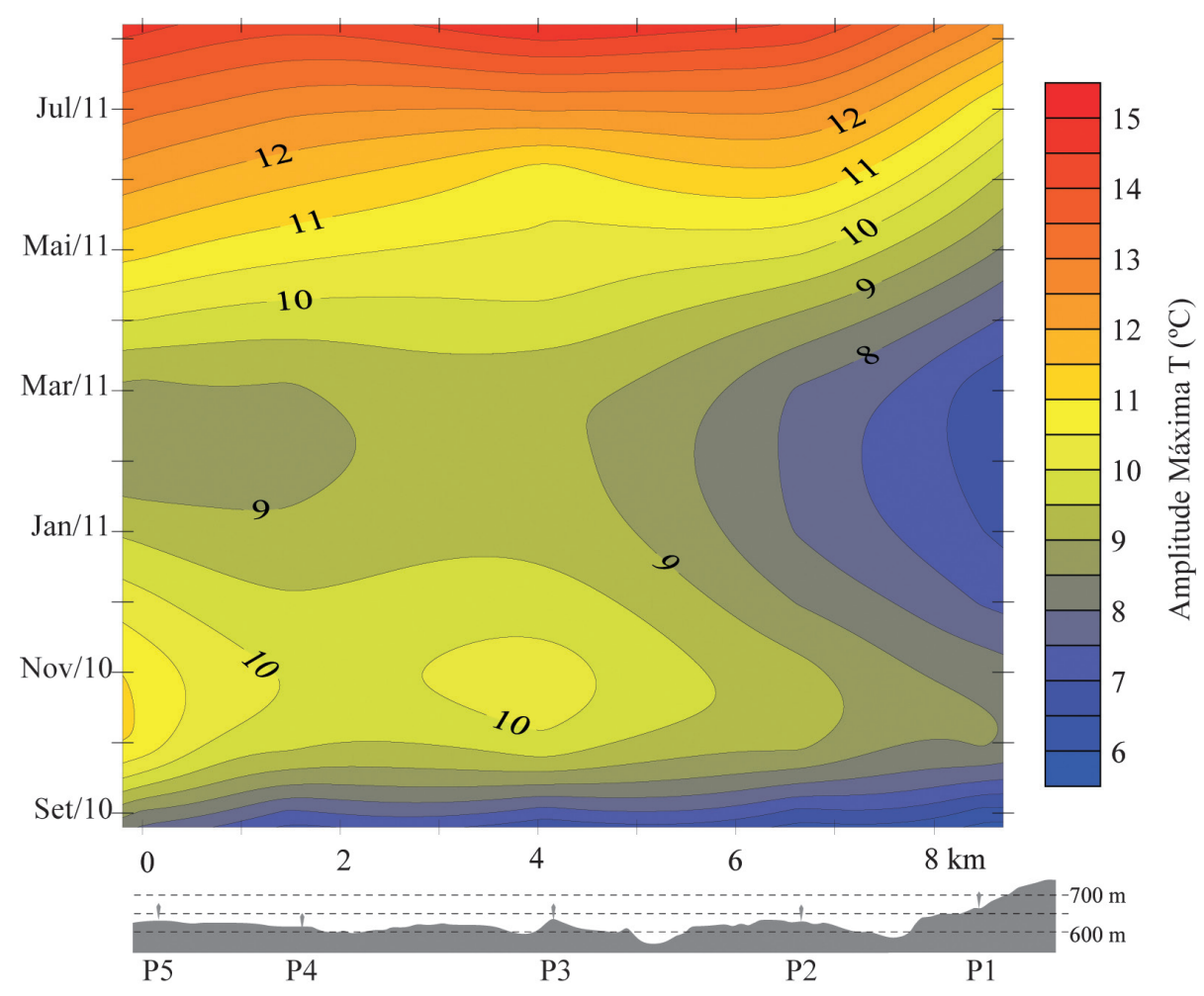

FIGURA 4 - Variação temporo-espacial das amplitudes térmicas médias mensais do período monitorado (setembro/2010 a agosto/2011) entre a FEENA e a área urbana de Rio Claro. 
À medida que se modifica a cobertura e uso da terra de um lugar a partir de suas condições originais, outros controles passam a interferir na temperatura do ar, tais como a arquitetura foliar da vegetação e o processo de urbanização. Assim, assumindo que P1 represente $100 \%$ das condições originais $\left(R^{2}=1\right)$, a temperatura em P2 é modificada em relação a P1 em cerca de 3,78\% $\left(\mathrm{R}^{2}=0,9622\right), \mathrm{P} 3 \mathrm{em}$ $4,64 \%\left(\mathrm{R}^{2}=0,9536\right), \mathrm{P} 4$ em $5,76 \%\left(\mathrm{R}^{2}=0,9424\right)$ e $\mathrm{P} 5$ em $6,16 \%\left(\mathrm{R}^{2}=0,9384\right)$. Evidentemente não é possível atribuir essas mudanças exclusivamente às modificações na cobertura e uso da terra, uma vez que uma parcela dessas diferenças pode ser

T P1 $\left({ }^{\circ} \mathrm{C}\right): \mathrm{T} \mathrm{P} 2\left({ }^{\circ} \mathrm{C}\right): \mathrm{r}^{2}=0,9622 ; y=-2,3911+1,1116^{\star} \mathrm{x}$

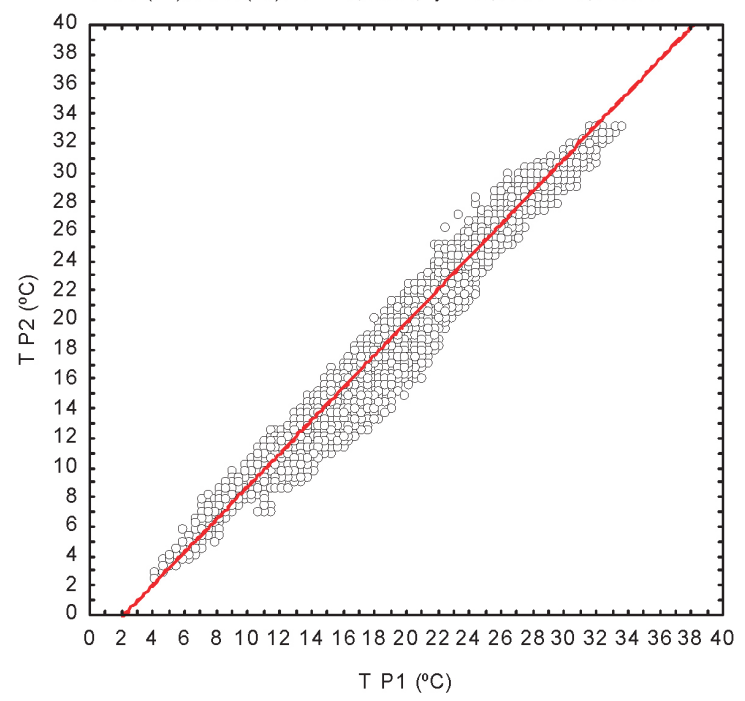

T P1 $\left({ }^{\circ} \mathrm{C}\right): \mathrm{T} \mathrm{P} 4\left({ }^{\circ} \mathrm{C}\right): r^{2}=0,9424 ; y=-0,1203+1,0894^{*} \mathrm{X}$

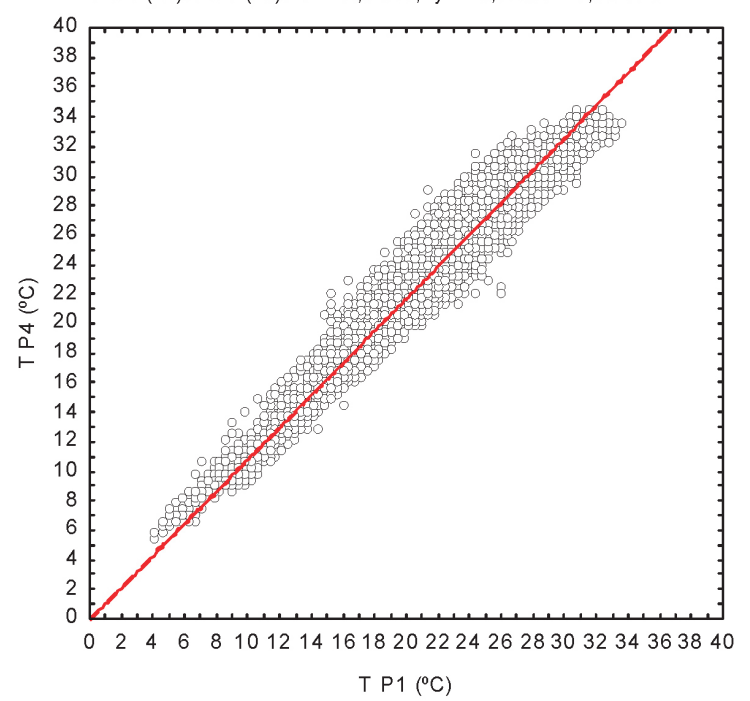

decorrente das pequenas diferenças de altitude (Tabela 1), da topografia (declividade, exposição das vertentes), hidrografia, entre outros controles climáticos naturais. Muitos trabalhos já indicaram efeitos semelhantes na temperatura do ar decorrentes da urbanização (TARIFA 1981, LOMBARDO 1985, GEIGER 1990, AMORIN 2000, JARDIM 2001, TARIFA \& ARMANI 2001, ANUNCIAÇÃO \& SANT'ANNA NETO 2002, ARAÚJO \& SANT'ANNA NETO 2002, SILVA et al. 2002, TAVARES 2002, LANDSBERG 2006, ARMANI et al. 2008, SANTOS JUNIOR \& CHRISTOFOLLETTI 2008, ARMANI et al. 2010, entre outros).
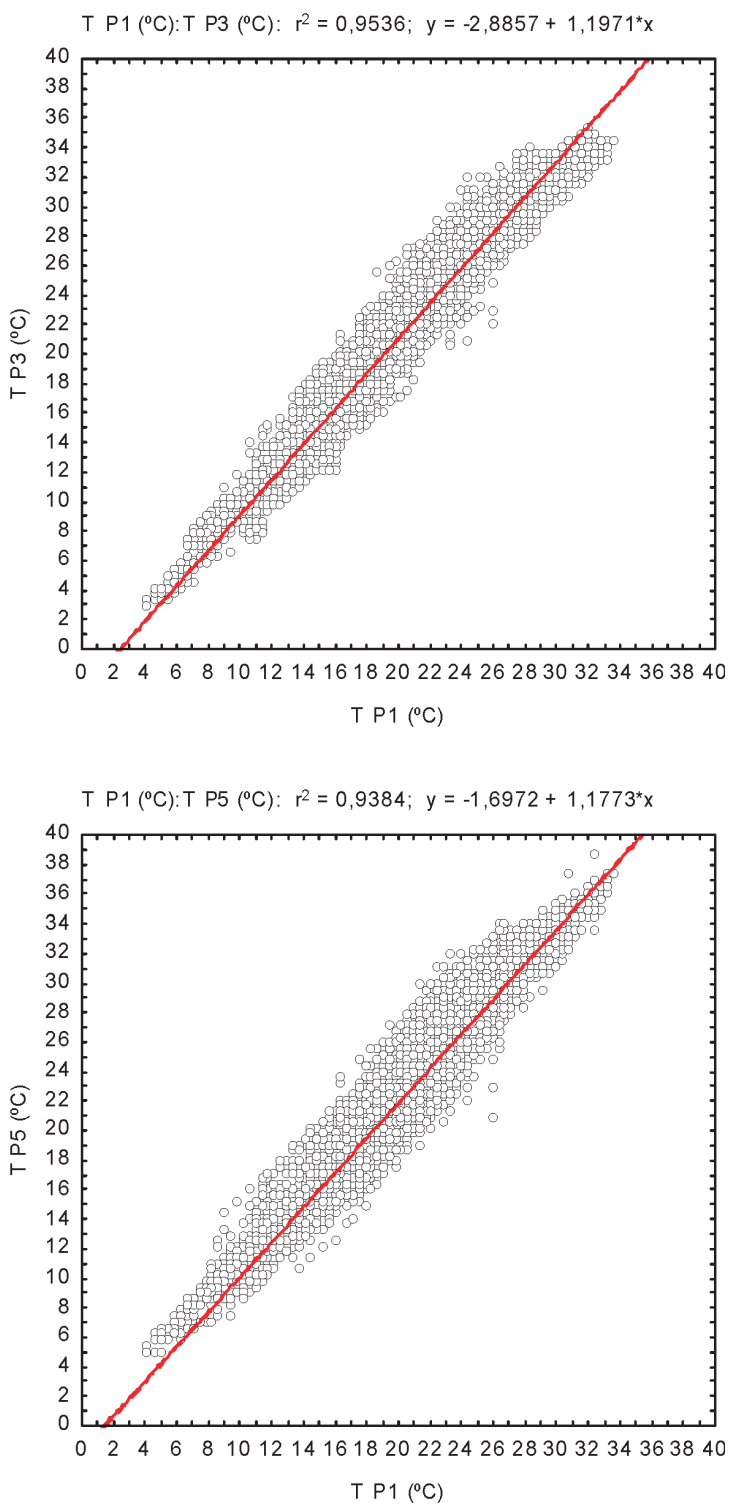

FIGURA 5 - Análise de regressão linear simples entre as temperaturas do ar em P2, P3, P4, P5 em relação a P1 (a partir dos dados brutos [30'] - setembro/2010 a agosto/2011). 
Ainda é possível notar que P2 e P3, em altitudes inferiores a P1, apresentam temperaturas mínimas inferiores a este último, decorrentes de inversões térmicas e também de um dossel florestal mais aberto e de uma estrutura da arquitetura foliar mais simples e verticalizada, que facilita trocas verticais de energia. Em relação às maiores temperaturas, P1 e P2 são relativamente semelhantes (valores em torno de $33,4^{\circ} \mathrm{C}$ ), enquanto $\mathrm{P} 3$ se aquece mais, com $35,3{ }^{\circ} \mathrm{C}$ de máxima absoluta (Figura 5, Tabela 2).

As temperaturas mínimas e máximas dos postos da área urbana (P4 e P5) são maiores que as observadas em P1(Figura 5, Tabela 2). Pode-se assumir que a urbanização produziu uma transformação no balanço de energia, resultante de mudanças na absorção, armazenamento e propagação da energia, bem como pela dissipação de energia inerente às atividades urbanas. As temperaturas mínimas estão na faixa de $5{ }^{\circ} \mathrm{C}$ em P4 e P5, e $4,2^{\circ}$ $\mathrm{C}$ em $\mathrm{P} 1$. Os postos da área urbana, em cotas altimétricas inferiores a P1 ( $\approx 35 \mathrm{~m}$ abaixo), registraram temperaturas superiores. Tal fato demonstra que o papel da cidade no armazenamento de energia e a consequente emissão de calor ao longo da noite é suficientemente grande para durar a noite toda e manter as temperaturas maiores que as da floresta nativa, mesmo sob situações de inversão térmica. Nas áreas urbanizadas, onde a umidade tende a ser menor (TARIFA 1981, OKE 1982, LOMBARDO 1985, GEIGER 1990, JARDIM2001, LANDSBERG 2006, ARMANI et al. 2008, ARMANI et al. 2010, entre outros), a retenção do calor pela estrutura urbana manteve a temperatura maior que nas áreas florestadas ao longo das noites mais frias e sob inversão térmica (Figura 5, Tabela 2), quando a perda noturna de radiação é maior devido à menor umidade no ar.

Durante o período de maior aquecimento, $\mathrm{P} 4$ e P5 apresentam-se sempre com temperaturas mais elevadas que P1 (P4 cerca de $1{ }^{\circ} \mathrm{C}$ a mais, e P5 em torno de $4{ }^{\circ} \mathrm{C}$, Figura 5), corroborando os resultados de ARMANI et al. (2010) e SANTOS JUNIOR \& CHRISTOFOLLETTI (2008) para a cidade de Rio Claro, ANUNCIAÇÃO \& SANT'ANNA NETO (2002) para Campo Grande (MS), TAVARES (2002) para Sorocaba (SP) e JARDIM (2001) para a bacia do Rio Aricanduva em São Paulo (SP).

Os resultados das análises de regressões realizadas a partir das temperaturas médias, mínimas e máximas diárias (Figura 6) assemelham-se àqueles obtidos com os dados brutos (Figura 5), mas com algumas diferenças. As temperaturas máximas diárias são as que apresentam os menores coeficientes de determinação em relação a P1. As temperaturas mínimas e médias diárias se ajustaram melhor ao modelo de regressão (Figura 6). Isso é função das propriedades térmicas dos materiais que compõem os ambientes urbanos, da geometria das ocupações e da dissipação de energia pelas atividades urbanas (calor antropogênico). A alteração no balanço de energia ficou mais evidente nos horários de máximo aquecimento, produzindo maior dispersão dos dados de temperatura máxima. A dispersão dos dados de temperatura mínima foi menor, porque a energia no ambiente é residual - armazenada durante o dia anterior e dissipada ao longo da noite. No entanto, essa energia foi suficiente para alterar a taxa de resfriamento na área urbana (P4 e P5), quando comparado à P1 (Figura 6).

Os desvios de temperatura de P2, P3, P4 e P5 em relação a $\mathrm{P} 1$ tendem a ser positivos e aumentam progressivamente de $\mathrm{P} 2$ para $\mathrm{P}$, sendo válidos para os períodos noturno e diurno (Tabela 3). Os desvios negativos de $\mathrm{P} 2$ e $\mathrm{P} 3$ ocorrem com maior frequência à noite, pois são oriundos de inversões térmicas, associadas às menores altitudes de $\mathrm{P} 2 \mathrm{e}$ P3, assim como do dossel mais aberto e da arquitetura foliar mais simples destes locais.

TABELA 3 - Frequência relativa (\%) de desvios absolutos entre P2, P3, P4 e P5 em relação a P1, por período (noturno e diurno).

\begin{tabular}{|c|c|c|c|c|c|c|}
\hline & & $\begin{array}{c}\text { Classes } \\
\text { de Desvios } \\
\left({ }^{\circ} \mathrm{C}\right)\end{array}$ & $P 2-P 1$ & $P 3-P 1$ & $P 4-P 1$ & $P 5-P 1$ \\
\hline \multirow{18}{*}{ 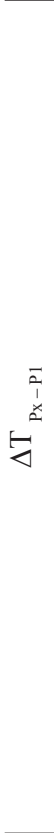 } & \multirow{9}{*}{ 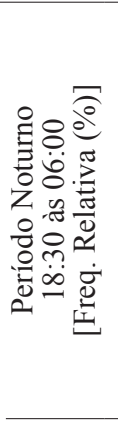 } & $<=-1$ & 31,2 & 8,6 & 0,0 & 0,1 \\
\hline & & $<=-0,1$ & 23,8 & 12,8 & 1,4 & 1,3 \\
\hline & & 0 & 26,9 & 19,7 & 6,0 & 5,4 \\
\hline & & $>=0,1$ & 17,9 & 39,3 & 34,2 & 35,0 \\
\hline & & $>=1$ & 0,2 & 14,8 & 37,6 & 41,3 \\
\hline & & $>=2$ & 0,0 & 3,3 & 10,6 & 9,5 \\
\hline & & $>=3$ & 0,0 & 1,4 & 7,5 & 5,6 \\
\hline & & $>=4$ & 0,0 & 0,2 & 2,0 & 1,4 \\
\hline & & $>=5$ & 0,0 & 0,0 & 0,6 & 0,3 \\
\hline & \multirow{9}{*}{ 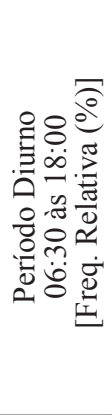 } & $<=-1$ & 6,4 & 3,6 & 0,4 & 2,6 \\
\hline & & $<=-0,1$ & 13,7 & 6,0 & 2,3 & 4,9 \\
\hline & & 0 & 19,7 & 6,8 & 3,8 & 4,2 \\
\hline & & $>=0,1$ & 45,8 & 18,9 & 18,4 & 13,6 \\
\hline & & $>=1$ & 14,3 & 43,2 & 53,2 & 36,7 \\
\hline & & $>=3$ & 0,1 & 20,0 & 19,7 & 30,4 \\
\hline & & $>=5$ & 0,0 & 1,3 & 2,1 & 6,9 \\
\hline & & $>=7$ & 0,0 & 0,1 & 0,1 & 0,5 \\
\hline & & $>=8$ & 0,0 & 0,0 & 0,0 & 0,1 \\
\hline
\end{tabular}

$\mathrm{x}$ variando de 2 a 5 

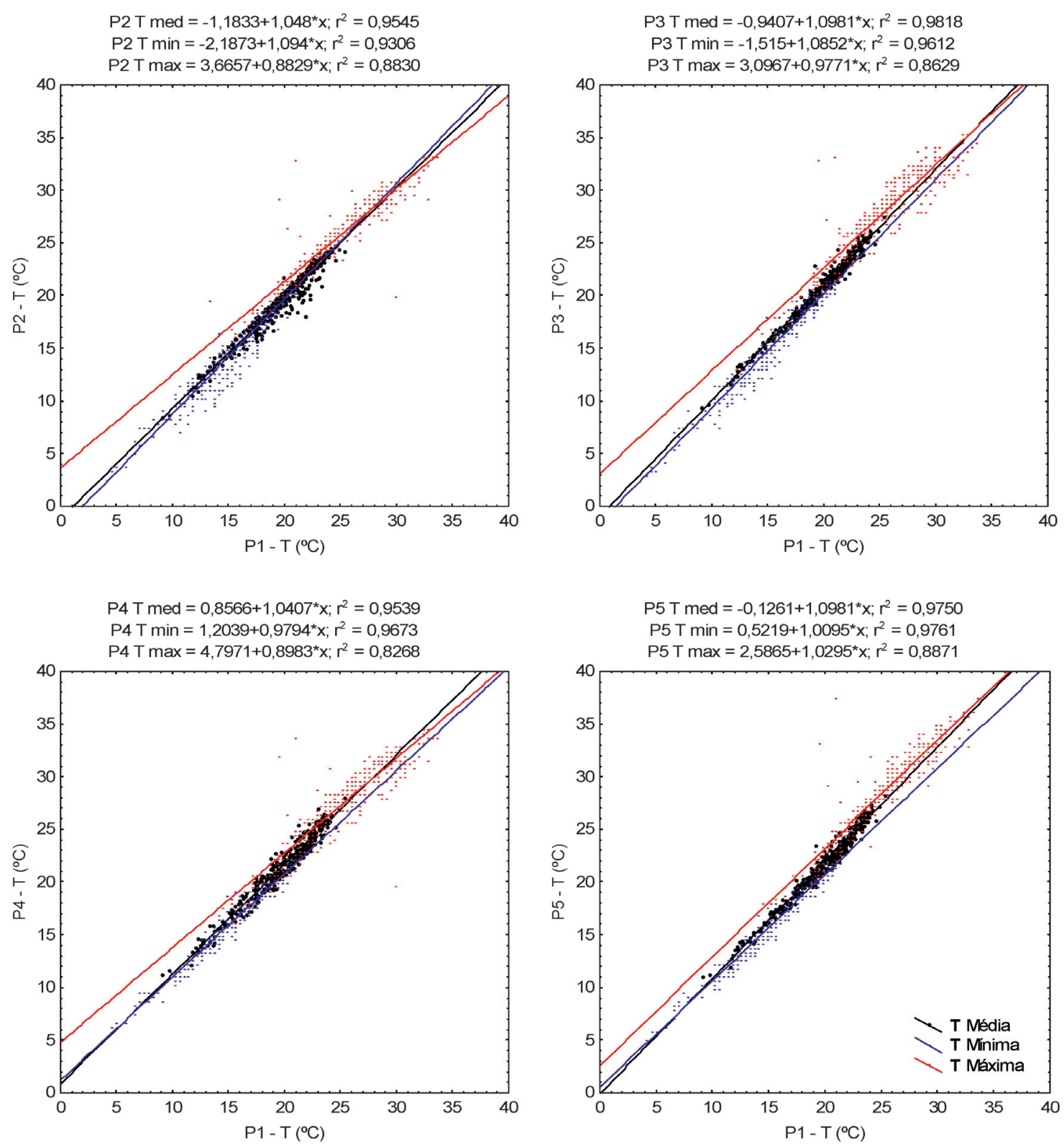

FIGURA 6 - Análise de regressão linear simples entre as temperaturas mínimas, médias e máximas diárias do ar em P2, P3, P4, P5 em relação a P1 (setembro/2010 a agosto/2011).

Entre $\mathrm{P} 1$ e os postos da área urbana (P4 e P5), observa-se que os desvios positivos são maiores e muito mais frequentes do que os observados em relação a P2 e P3. P5 apresentou os maiores desvios (Tabela 3), sendo as classes de $1{ }^{\circ} \mathrm{C}$ a $3{ }^{\circ} \mathrm{C}$ as de maior frequência; os máximos $\left(>8^{\circ} \mathrm{C}\right)$ ocorreram no período diurno, e representaram $0,1 \%$ do período, cerca de $8 \mathrm{~h}$ ao longo de todo o ano monitorado.

Esses resultados podem ser interpretados em função dos materiais utilizados na área urbana da cidade em substituição à floresta, pois alteram o balanço de radiação e consequentemente o de energia, aumentando a quantidade de calor sensível sobre as áreas urbanas em detrimento ao calor latente de evaporação, que é maior nas áreas florestadas. Além disso, o armazenamento de energia nas estruturas urbanas também interfere nesses resultados, como indicado pelos desvios positivos no período noturno registrados nos postos da área urbana (P4 e P5), muito mais frequentes que nas áreas florestadas. A alteração no balanço de energia manifestou-se melhor nos horários de máximo 


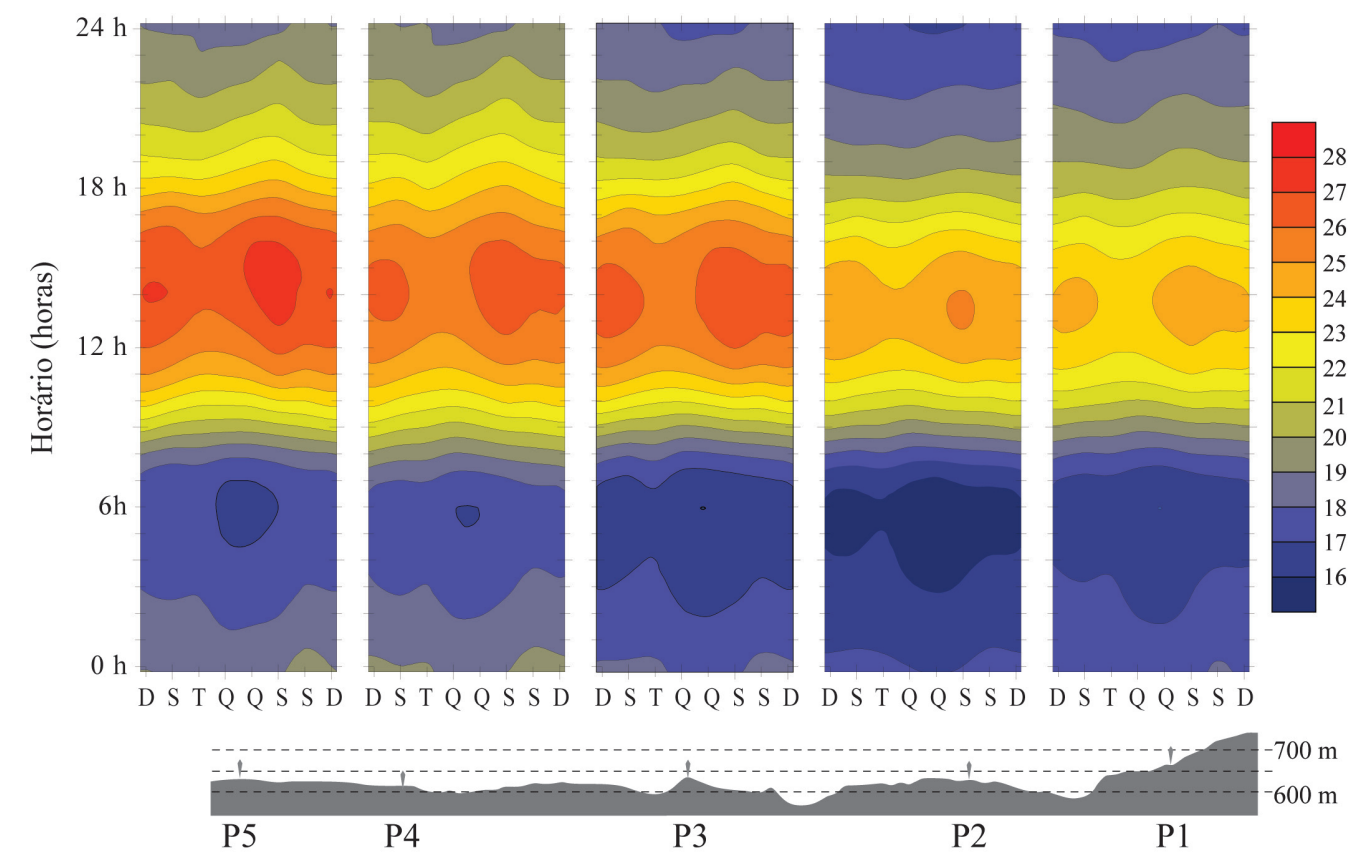

FIGURA 7 - Temperatura média horária do ar por dia da semana nos cinco postos microclimáticos (setembro/2010 a agosto/2011).

aquecimento, embora no período noturno a energia residual da área urbana (armazenada no dia anterior) tenha sido suficiente para manter os desvios de temperatura positivos em relação à FEENA (P1) (Tabela 3).

Considerando as médias horárias da temperatura do ar por dias da semana (Figura 7), verifica-se em todos os postos um aquecimento pronunciado entre as $14 \mathrm{e} 16 \mathrm{~h}$, progressivamente mais intenso de $\mathrm{P} 1$ para $\mathrm{P} 5$, o que está diretamente associado às diferenças na cobertura e uso da terra. Os maiores resfriamentos ocorrem em torno das $6 \mathrm{~h}$ da manhã e, em geral, são mais intensos em P1 e P2, concordando com os resultados das análises de regressão (Figuras 5 e 6). Observa-se que P2 atinge as menores temperaturas médias, fato relacionado às inversões térmicas (Figura 7).

$\mathrm{Na}$ variação horária da temperatura ao longo dos dias da semana percebe-se que terça-feira foi o dia da semana com menores resfriamento e aquecimento, enquanto quinta e sexta-feira, os dias com maiores aquecimento e resfriamento (Figura 7). Esses resultados apontam para a existência de um ritmo semanal, sendo sexta-feira o dia da semana com maior aquecimento e terça-feira, o menor. Apesar disso reforçar a hipótese de que o ritmo das atividades humanas constitui um dos elementos determinantes nos processos que ocorrem na baixa troposfera (AZEVEDO 2001a), fica difícil justificar o menor aquecimento na terça-feira (dia útil), em detrimento ao sábado e domingo (dias não úteis). AZEVEDO (2001a) argumenta que o domingo seria o dia de menor quantidade de calor antropogênico e quarta-feira o de máximo, caso fosse acumulada a energia dissipada ao longo de vários meses ou anos, pois as pontes de feriados concentram-se às segundas e sextas-feiras. $\mathrm{O}$ autor demonstra evidências desse ritmo semanal na Região Metropolitana de São Paulo (RMSP). No entanto, acredita-se que o ritmo semanal observado nas temperaturas médias por dia da semana em Rio Claro se deva a uma coincidência da dinâmica dos sistemas atmosféricos ao longo do período monitorado (setembro 2010 - agosto 2011).

A maior frequência, ou intensidade, de frentes polares ocorreu às terças-feiras, o que causou as menores amplitudes térmicas observadas. Na quarta-feira a entrada da alta migratória polar dá início ao aumento progressivo da estabilidade atmosféri$\mathrm{ca}$, induzindo maior resfriamento durante a noite e maior aquecimento ao longo do dia. Este fato intensifica-se com o aumento da pressão atmosférica, à medida que o anticiclone migratório polar avança para norte, produzindo aumento progressivo da estabilidade atmosférica na quinta e sexta-feira, acompanhado de sua tropicalização. Isso amplifica a amplitude térmica diária, quanto mais se distancia da terça-feira. No sábado e domingo o sistema 
estaria tropicalizado e produzindo nebulosidade suficiente para atenuar o aquecimento/resfriamento ao longo do dia/noite. Fato semelhante foi descrito por FARIAS \& BRANDÃO (2010) em um estudo aplicado ao bairro do Maracanã na cidade do Rio de Janeiro.

Os desvios entre as temperaturas médias de P2, P3, P4 e P5 em relação a P1, calculados por horário e dias da semana, confirmam que o ritmo semanal existe, inclusive dentro da FEENA, sendo que o desvio positivo é maior à medida que se altera a cobertura e uso da terra, desde a floresta nativa até uma área densamente urbanizada (Figura 8). Os valores máximos dos desvios positivos ocorreram na quinta e sexta-feira entre 16 e $18 \mathrm{~h}$, e são mais elevados nas áreas urbanas. Desvios negativos só ocorrem em P2 e P3, cujas altitudes são inferiores a P1. Esses desvios estão relacionados à drenagem noturna de ar frio para as áreas mais baixas (P2 e P3) nas florestas e ao dossel mais aberto que aquele encontrado em P1 (floresta nativa). Em P4 e P5 os desvios negativos nas médias horárias por dias da semana não ocorrem, fato atribuído às alterações no balanço de energia, decorrentes da urbanização, conforme já discutido anteriormente.
P5, que corresponde a um ambiente densamente construído, possui maior capacidade de armazenar calor e, provavelmente, emite ondas longas por um período maior de tempo, reduzindo o resfriamento ao longo da noite. O calor retido pela estrutura (forma e conteúdo) da cidade é disssipado mais lentamente que nas áreas florestadas ou com urbanização de menor densidade. Isso contribui para a manutenção da temperatura mais elevada no período noturno nas áreas urbanizadas. Esses resultados corroboram aqueles apresentados por ARMANI et al. (2010), GREGÓRIO \& BRANDÃO (2010) e LIMA et al. (2010) para cidades médias e grandes no trópico brasileiro.

Todavia, o cálculo do desvio absoluto entre as médias horárias possibilita, ainda que limitadamente, a distinção entre os ritmos urbano e natural. O aumento do valor do desvio entre 16 e $17 \mathrm{~h}$, quando analisado junto à escala de tempo semanal, sugere um incremento de energia por parte das atividades urbanas, associado à dissipação do calor antropogênico. Esse valor é maior nas áreas urbanizadas do que na FEENA. Essa energia acumula-se ao longo da semana e tem seu ápice nos últimos dias úteis (quinta e sexta-feira). Mesmo assim, esse

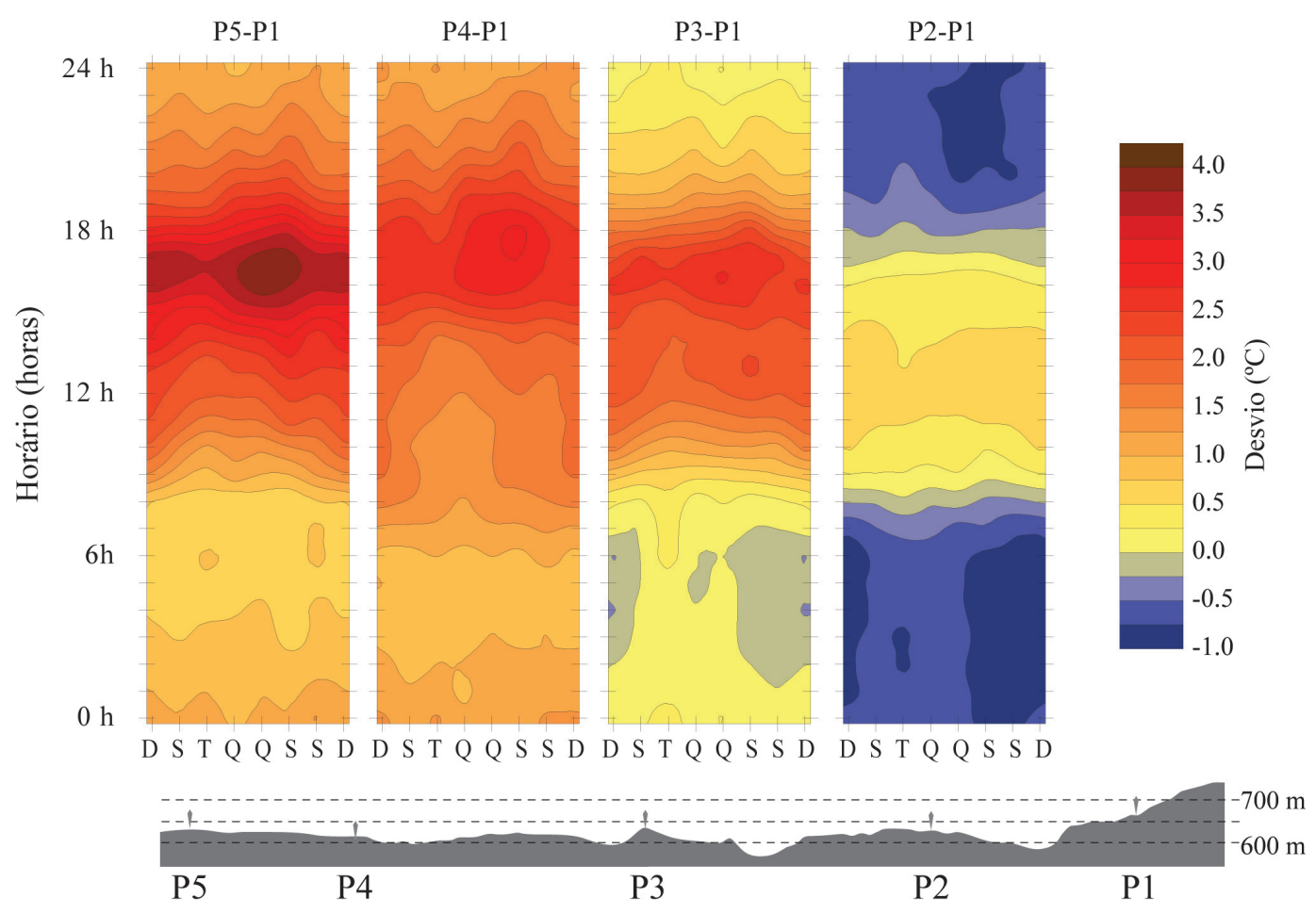

FIGURA 8 - Desvios da temperatura média horária do ar por dia da semana em P2, P3, P4, P5 em relação a P1 (setembro/2010 a agosto/2011). 
resultado deve ser tomado com ressalva, pois Rio Claro é uma cidade de porte médio e, como tal, não é diretamente comparável a RMSP, conforme apresentado por AZEVEDO (2001a, b).

O ritmo semanal (7 dias), a princípio, tem sua origem associada às atividades humanas (AZEVEDO 2001a). A análise espectral de Fourier aplicada aos dados revelou que este ciclo existe em todos os postos (Figura 9), aumentando sua intensidade ( $>$ densidade espectral) de P1 a P5, ou seja, diretamente proporcional às modificações na cobertura e uso da terra, desde a floresta nativa até uma área densamente urbanizada. Os postos P4 e P5 tem praticamente a mesma densidade espectral $(\sim 700$ ${ }^{\circ} \mathrm{C}^{2}$ ), pois estão imersos na malha urbana da cidade e recebem diretamente o fluxo de energia antropogênica. Na FEENA a densidade espectral deste ciclo diminui para metade do valor encontrado na área urbanizada, cerca de $400{ }^{\circ} \mathrm{C}^{2}(\mathrm{P} 1)$, e sugere que a energia dissipada pelas atividades urbanas influencia o ritmo térmico dentro da floresta (Figura 9). Evidentemente essa densidade espectral é muito tênue em relação aos grandes ciclos existentes, principalmente aqueles relacionados à radiação solar, com densidade espectral da ordem de 32.000 ${ }^{\circ} \mathrm{C}^{2}$ para o ciclo diário $(24 \mathrm{~h})$.

Os resultados obtidos neste trabalho sugerem que os desvios de temperatura do ar em relação àqueles obtidos na floresta de árvores nativas tendem a ser maiores, quanto maior for a alteração na cobertura e uso da terra. No entanto, não é possível comprovar que essa relação seja direta e/ou linear, como aqui sugerido. Em alguns casos o lugar pode ser modificado para que se atinja determinado grau de conforto ou limites térmicos (BROWN 2010), podendo se tornar relativamente próximo, ao menos numericamente, daquilo que seria uma floresta nativa. TARIFA \& ARMANI $(2000,2001)$ revelaram que os bairros nobres, e até mesmo a área central da cidade de São Paulo, apresentam temperaturas mais próximas daquelas das áreas florestadas do entorno.

MONTEIRO (1976) afirmou que a despeito de todos os erros acumulados e resultados nocivos da alteração do clima nas cidades, o jogo das relações envolvido na produção do espaço geográfico leva a crer na possibilidade de que o homem conduza a evolução do clima urbano a metas superio-

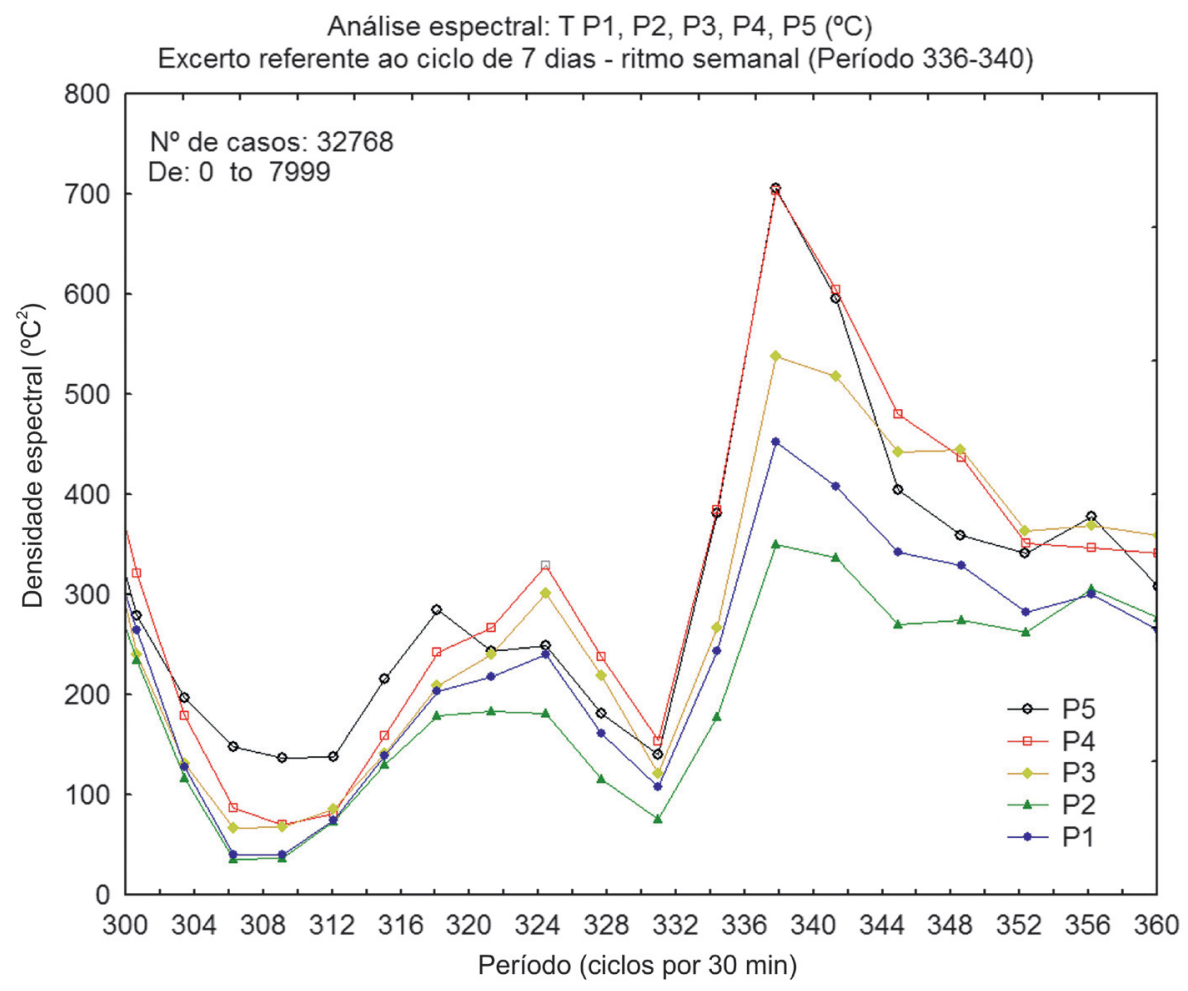

FIGURA 9 - Análise espectral de Fourier das séries de temperatura do ar nos cinco ambientes microclimáticos (setembro/2010 a agosto/2011). 
res de qualidade de vida, desde que, com percepção justa e decisões adequadas, dirija a evolução dele para o bem geral da sociedade. Isso ficou evidente a partir das constatações de TARIFA \& ARMANI $(2000,2001)$ para a cidade de São Paulo, mas essa evolução dirigida ocorreu somente onde interessava àqueles que detêm o "poder".

Em uma análise crítica dos resultados alcançados, percebe-se que sua validade está restrita ao período de análise (setembro/2010 a setembro/2011) e às técnicas empregadas. A deficiência na densidade amostral da temperatura limitou o tratamento espacial, bem como a ausência de medidas em perfis verticais e de transectos móveis em diversas situações sinóticas restringiram as possibilidades de interpretação e o alcance das conclusões.

Como continuidade desta investigação pretende-se relacionar os dados do monitoramento com imagens de sensores orbitais do canal infravermelho distante (termal) para a melhor compreensão das interações entre a temperatura do ar e os padrões de cobertura e uso da terra, bem como realizar o detalhamento no tratamento da dinâmica dos estados atmosféricos, utilizando-se da análise rítmica (MONTEIRO 1971) e dos fluxos polares (MONTEIRO 1969, TARIFA 1975, ARMANI \& GALVANI 2011). A sucessão, retorno, e duração dos tipos de tempo e estados atmosféricos aliados à análise dos fluxos polares permitirá compreender como a temperatura é influenciada pela circulação atmosférica em interação com os diferentes padrões de cobertura e uso da terra.

\section{CONCLUSÕES}

Com base na análise dos gradientes de temperatura do ar em diferentes padrões de cobertura e uso da terra em Rio Claro, pôde-se concluir que:

1) O padrão de cobertura e uso da terra influencia a temperatura do ar, produzindo desvios positivos na temperatura, quanto mais urbanizado for o lugar. Os desvios entre a área de floresta nativa e a área mais urbana apresentaram uma magnitude média de $1,7^{\circ} \mathrm{C}$ no outono e de $2,0^{\circ} \mathrm{C}$ no verão e inverno, sendo mais intenso quanto maior a densidade da urbanização. O máximo desvio entre $\mathrm{P} 1$ e $\mathrm{P} 5$ observado atingiu $8,7^{\circ} \mathrm{C}$ durante o dia, e à noite, $6,9^{\circ} \mathrm{C}$;

2) As diferenças altimétricas entre os postos foram suficientes para minimizar os gradientes de temperatura entre os tipos de composição de floresta (nativa, reflorestamento+nativa, reflorestamento), indicando que o efeito topoclimático se sobre- pôs àquele relacionado ao tipo de vegetação. Essas situações ocorreram nas madrugadas, favorecidas pela drenagem noturna de ar frio. Nas áreas urbanas o efeito topoclimático não foi suficientemente forte para disfarçar os efeitos oriundos da alteração na cobertura e uso da terra, mesmo sob situações de inversão térmica;

3) Considerando-se que o Brasil é um país eminentemente tropical, com excedente de calor no ambiente na maior parte do ano, as florestas produzem ambientes com menor ganho de calor, ao passo que as áreas urbanas acentuam o já existente excedente de calor ambiental. A estrutura maior e mais complexa das matas tropicais nativas são de grande importância, pois atenuam o calor mais efetivamente que as florestas de estruturas mais simples, por exemplo, de reflorestamento de eucaliptos;

4) A dinâmica urbana, a partir de suas atividades e funções, atua como agente transformador do clima das cidades. Sua influência é sensivelmente percebida nas amplitudes térmicas, bem como na criação de um ritmo oriundo das atividades urbanas (ciclo de sete dias).

\section{AGRADECIMENTOS}

Os autores agradecem ao Instituto Geológico/SMA pelo financiamento da pesquisa (proc.: 11.122/2010), ao Instituto Florestal/SMA, à Faculdade Claretianas e à UNESP por terem viabilizado a instalação dos equipamentos com segurança em seus territórios, e aos relatores da Revista do Instituto Geológico pelas sugestões e críticas valiosas.

\section{REFERÊNCIAS BIBLIOGRÁFICAS}

ALMEIDA, F.F.M. 1964. Fundamentos geológicos do relevo paulista. Boletim do Instituto Geográfico e Geológico, 41:169-263.

AMORIN, M.C.C.T. 2000. O clima urbano de Presidente Prudente/SP. Faculdade de Filosofia, Letras e Ciências Humanas, Universidade de São Paulo, São Paulo, Tese de Doutorado, 374 p.

ANUNCIAÇÃO, V.S.; SANT'ANNA NETO, J.L. 2002. O clima urbano da cidade de Campo Grande - MS. In: J.L. Sant'Anna Neto (org.) O clima das cidades brasileiras. Presidente Prudente, UNESP, p. 61-87.

ARAÚJO, R.R.; SANT'ANNA NETO, J.L. 2002. $O$ processo de urbanização na produção do 
clima urbano de São Luís - MA. In: J. L. Sant'Anna Neto (org.) O clima das cidades brasileiras. Presidente Prudente, UNESP, p. 21-41.

ARMANI, G.; GALVANI, E. 2006. Avaliação de um abrigo meteorológico de baixo custo. Revista Brasileira de Agrometeorologia, 14(1): 116-122.

ARMANI, G; GALVANI, E. 2011. Fluxos polares e o ritmo dos sistemas atmosféricos no nordeste do estado de São Paulo. Sociedade \& Natureza, 23: 7-22.

ARMANI, G.; FUNARI, F.L.; SALUM, S.T. 2008. Ocorrência do orvalho na cidade de São Paulo. Revista do Instituto Geológico, 29(12): 41-48.

ARMANI, G.; MAGALHÃES, R.S.B.; CHRISTOFOLETTI, S.R.; TIMONI, J.L.; ROVIELO, A.L. 2010. Análise microclimática comparativa entre a Floresta Estadual Edmundo Navarro de Andrade e a área urbana de Rio Claro - SP. HOLOS Environment (Online), 10: 30-50.

AZEVEDO, T. R. 2001a. Derivação antrópica do clima na Região Metropolitana de São Paulo abordada como função do ritmo semanal das atividades humanas. Faculdade de Filosofia, Letras e Ciências Humanas, Universidade de São Paulo, São Paulo, Tese de Doutorado, 475 p.

AZEVEDO, T.R. 2001b. O fluxo de calor gerado pelas atividades humanas. In: J.R. Tarifa. \& T.R. Azevedo (org.) Os climas na cidade de São Paulo: teoria e prática. São Paulo, GEOUSP (Coleção Novos Caminhos, 4), p.71-93.

BROWN, R.D. 2010. Design with microclimate: the secret to comfortable outdoor space. Washington, Island Press, $180 \mathrm{p}$.

CARFAN, A.C. 2011. Análise de conforto térmico em áreas abertas no município de Ourinhos SP. Faculdade de Filosofia, Letras e Ciências Humanas, Universidade de São Paulo, São Paulo, Tese de Doutorado, 362 p.

CARMO, J.A. 2006. Dinâmicas Sócio-Espaciais na Cidade de Rio Claro (SP): As Estratégias Econômicas, Políticas e Sociais na Produção do Espaço. Instituto de Geociências e Ciências Exatas, Universidade Estadual Paulista, Rio Claro, Dissertação de Mestrado, 202 f.
CEAPLA - CENTRO DE ANÁLISE E PLANEJAMENTO AMBIENTAL /IGCE-UNESP -INSTITUTO DE GEOCIÊNCIAS E CIÊNCIAS EXATAS - UNIVERSIDADE ESTADUAL PAULISTA. 2014. Estação meteorológica. Centro de Análise e Planejamento Ambiental, Universidade Estadual Paulista. Disponível em http://www.rc.unesp.br/igce/ceapla/. Acessado em 18 abr. 2014.

CPLA - COORDENADORIA DE PLANEJAMENTO AMBIENTAL; IG - INSTITUTO GEOLÓGICO. 2013. Mapeamento do Uso e Cobertura do Solo da UGRHI 5 (PCJ) - Escala 1:25.000. Secretaria do Meio Ambiente do Estado de São Paulo. Disponível em http:// www.ambiente.sp.gov.br/cpla/files/2013/02/ Ficha Tecnica Mapeamento UGRHI051.pdf. Acessado em 22 out. 2015.

COLTRI, P.P.; VELASCO, G.D.N.; POLIZEL, J.L.; DEMETRIO, V.A.; FERREIRA, N.J. 2007. Ilhas de calor na estação de inverno da área urbana do município de Piracicaba, SP. In: INPE, SIMPÓSIO BRASILEIRO DE SENSORIAMENTO REMOTO, 13, Florianópolis, Anais, p. 5151-5157.

FARIAS, H.S.; BRANDÃO, A.M.P.M. 2010. A influência antrópica na evolução semanal da temperatura do ar no bairro Maracanã/RJ. Revista Brasileira de Climatologia, 6: 7-22.

GEIGER, R. 1990. Manual de microclimatologia: o clima da camada de ar junto ao solo. Fundação Calouste Gulbenkian. Lisboa, 2.ed., $556 \mathrm{p}$.

GREGÓRIO, L.S.; BRANDÃO, A.M.P.M. 2010. O clima urbano de São João de Meriti/ RJ: um estudo aplicado à análise do campo térmico e ilhas de calor. Revista Brasileira de Climatologia, 7: 21-36.

IBGE - INSTITUTO BRASILEIRO DE GEOGRAFIA E ESTATÍSTICA. Cidades@. Disponível em http://cidades.ibge.gov.br/xtras/ home.php. Acessado em 10 out. 2014.

JARDIM, C.H. 2001. Os microclimas e o uso do solo no vale do rio Aricanduva. In: J.R. Tarifa. \& T.R. Azevedo (org.) Os climas na cidade de São Paulo: teoria e prática. São Paulo, GEOUSP (Coleção Novos Caminhos, 4), p.188-199. 
LANDSBERG, H.E. 2006. O clima das cidades. Revista do Departamento de Geografia, 18: 95-111.

LIMA, C.A.; DANNI-OLIVEIRA, I.M.; PERTSCHI, S.C. 2010. Considerações sobre a metodologia a respeito da alteração da temperatura do ar no ambiente urbano: estudo em São José dos Pinhais/PR. Revista Brasileira de Climatologia, 7: 37-46.

LOMBARDO, M.A. 1985. Ilha de calor nas metrópoles: o exemplo de São Paulo. Ed. HUCITEC, São Paulo, 244 p.

MONTEIRO, C.A.F. 1969. A Frente Polar Atlântica e as chuvas e inverno na fachada sul-oriental do Brasil (Contribuição metodológica à análise rítmica dos tipos de tempo no Brasil). Teses e Monografias - IGEOG/USP,1: 68 p.

MONTEIRO, C.A.F. 1971. Análise rítmica em Climatologia: problemas da atualidade climática em São Paulo e achegas para um programa de trabalho. Climatologia - IGEOG/ USP, 1, $21 \mathrm{p}$.

MONTEIRO, C.A.F. 1973. A dinâmica climática e as chuvas no Estado de São Paulo: estudo geográfico sob a forma de atlas. Instituto de Geografia da Universidade de São Paulo, São Paulo, 129 p.

MONTEIRO, C.A.F. 1976. Teoria e clima urbano. Teses e monografias - IGEOG/USP, 25: $181 \mathrm{p}$.

MONTEIRO, C.A.F. 1978. Derivações antropogênicas dos geossistemas terrestres no Brasil e alterações climáticas: perspectivas urbanas e agrárias ao problema da elaboração de modelos de avaliação. In: ACIESP- ACADEMIA DE CIÊNCIAS DO ESTADO DE SÃO PAULO - SECRETARIA DA CULTURA, CIÊNCIA E TECNOLOGIA, SIMPÓSIO SOBRE A COMUNIDADE VEGETAL COMO UNIDADE BIOLÓGICA, TURÍSTICA E ECONÔMICA, 15, Anais, p. 43-76.

MONTEIRO, C.A.F. 1990a. Adentrar a cidade para tomar-lhe a temperatura. Geosul, 5(9): 61-79.

MONTEIRO, C.A.F. 1990b. A cidade como processo derivador ambiental e a geração de um clima urbano: estratégias na abordagem geográfica. Geosul, 5(9): 80-114.
MONTEIRO, C.A.F.; TARIFA, J.R. 1977. Contribuição ao estudo do clima de Marabá: uma abordagem de campo ao planejamento urbano. Climatologia - IGEOG/USP, 7: 51 p.

OKE, T.R. 1982. The energetic basis of the urban heat island. Quarterly Journal of the Royal Meteorological Society, 108: 1-24.

ROSETTI, L.A.F.G.; PINTO, S.A.F.; ALMEIDA, C.M. 2007. Geotecnologias aplicadas à caracterização das alterações da cobertura vegetal intra-urbana e da expansão urbana da cidade de Rio Claro (SP). In: INPE, SIMPÓSIO BRASILEIRO DE SENSORIAMENTO REMOTO, 13, Florianópolis, Anais, p. 5479-5485.

SANTOS JUNIOR, E.F.; CHRISTOFOLETTI, A.L.H. 2008. Estudo da variabilidade microclimática da temperatura e umidade relativa em localidades na área central de Rio Claro-SP em dois episódios (inverno e verão). In: EDUFU, SIMPÓSIO BRASILEIRO DE CLIMATOLOGIA GEOGRÁFICA, 8, Alto Caparaó, Anais, p. 310-322.

SÃO PAULO. 2012. Atlas Eólico do Estado de São Paulo. Secretaria de Energia, Governo do Estado de São Paulo, São Paulo.

SEADE - FUNDAÇÃO SISTEMA ESTADUAL DE ANÁLISE DE DADOS. 2012. Informações dos municípios paulistas. Disponível em http:// www.seade.gov.br/banco-de-dados/. Acessado em 10 out. 2012.

SILVA, L.T.; TOMMASELLI, J.T.G.; AMORIN, M.C.C.T. 2002. O clima urbano de Penápolis - SP. In: J. L. Sant'Anna Neto (org.) O clima das cidades brasileiras. Presidente Prudente, UNESP, p.145-163.

SOUZA, D.M.; NERY, J.T. 2011. Parâmetros climáticos de Ourinhos, Estado de São Paulo. Acta Scientiarum. Human and Social Sciences, 33(1): 107-115.

TARIFA, J.R. 1975. Fluxos polares e as chuvas de primavera-verão no Estado de São Paulo: uma análise quantitativa do processo genético. Teses e Monografias- IGEOG/USP, 19: 93 p.

TARIFA, J.R. 1981. A análise topo e microclimática e o trabalho de campo: o caso de São José dos Campos. Climatologia - IGEOG/USP, 11: 25 p. 
TARIFA, J.R. 2001. O ritmo e a prática do estudo dos climas de São Paulo (1970-2000). In: J.R. Tarifa \& T.R. Azevedo (orgs.) Os climas na cidade de São Paulo: teoria e prática. São Paulo, GEOUSP (Coleção Novos Caminhos, 4), p. 11-33.

TARIFA, J.R.; ARMANI, G. 2000. Unidades climáticas urbanas da cidade de São Paulo (primeira aproximação). In: Atlas Ambiental do Município de São Paulo. Prefeitura do Município de São Paulo - SEMPLA/SVMA, São Paulo, 1v., CD-ROM.

TARIFA, J.R.; ARMANI, G. 2001. Os climas urbanos. In: J.R. Tarifa \& T.R. Azevedo (org.) Os climas na cidade de São Paulo: teoria e prática. São Paulo, GEOUSP (Coleção Novos Caminhos, 4), p. 47-70.

TAVARES, R. 2002. O clima de Sorocaba - SP. In: J. L. Sant'Anna Neto (org.) O clima das cidades brasileiras. Presidente Prudente, UNESP, p. 115-163.

VOOGT, J.A.; OKE, T.R. 1997. Complete Urban Surface Temperatures. Journal of Applied Meteorology, 36: 1117-1132.

\section{WMO - WORLD METEOROLOGICAL} ORGANIZATION. 2007. Data quality control. In: Guide to observation systems, 3rd. ed., $n^{\circ} 488$.

\section{Endereço dos autores:}

Gustavo Armani e Carolina Leocádio Pereira - Instituto Geológico, Secretaria de Estado de Meio Ambiente/SP, Rua Joaquim Távora, 822, Vila Mariana, CEP: 04015-001, São Paulo, SP, Brasil. E-mails: armani.gustavo@gmail.com, carolina.leocadio.pereira@usp.br

Sergio Ricardo Christofoletti - Instituto Florestal, Secretaria de Estado do Meio Ambiente de São Paulo, Av. Navarro de Andrade S/N, Vila Paulista, CEP: 13.500-970, Rio Claro, SP. E-mail: sergioricardoc@gmail.com

Artigo submetido em 15 de junho de 2015, aceito em 10 de novembro de 2015. 